\title{
ESTADO DEL PATRIMONIO CULTURAL INMUEBLE EN EL DEPARTAMENTO DE SANTANDER
}

Nahir Pabón Castro*

Edificio de la estación de ferrocarril de La Capilla, Puente Nacional - Santander 2008

Fuente: Archivo del autor

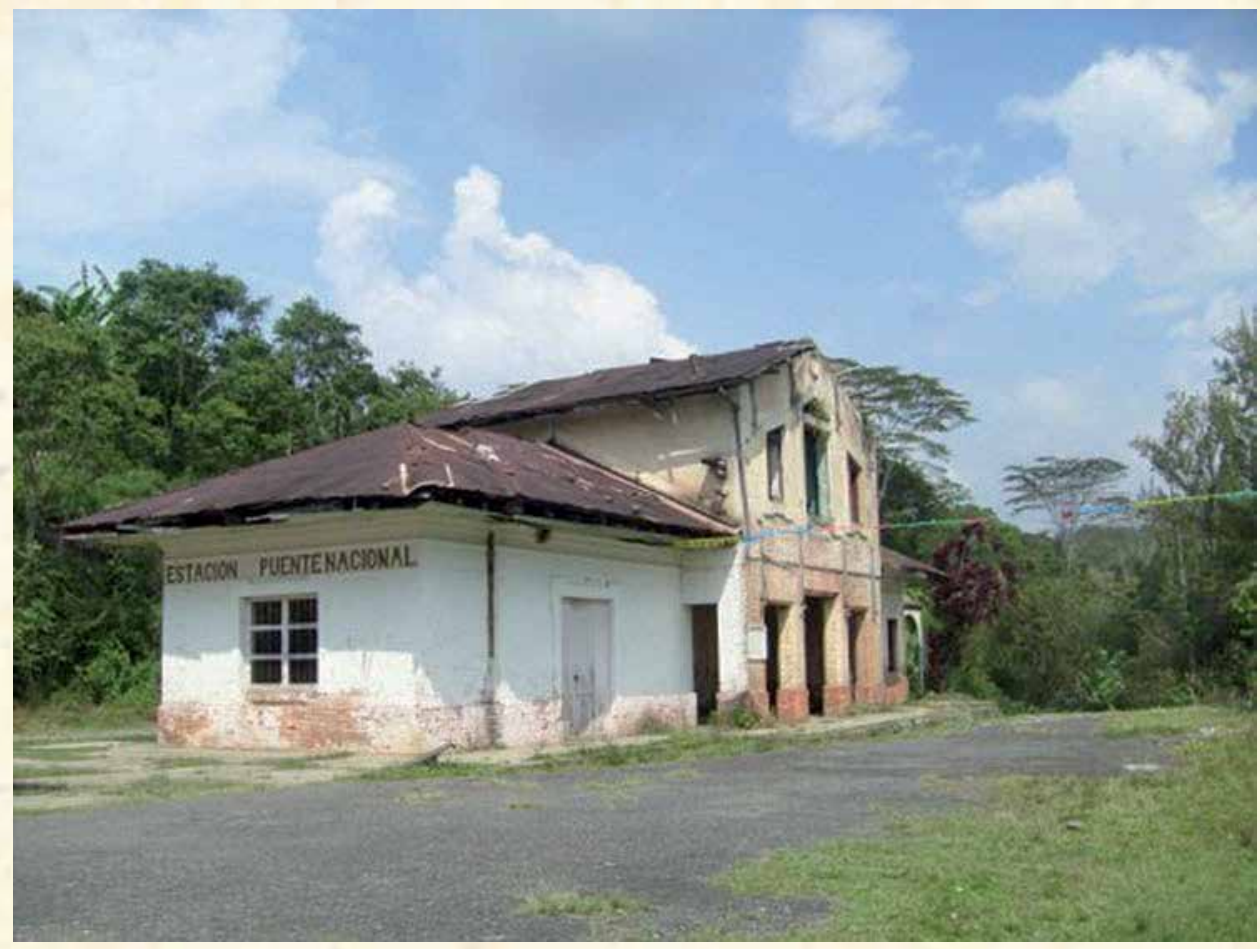

\section{RESUMEN}

El artículo hace parte de una investigación que tuvo por objeto el seguimiento del tema del Patrimonio Cultural Inmueble en el Departamento de Santander, a partir de la formulación de la Ley General de Cultura en 1997, como parte de la labor que se desarrolló al interior del Centro Filial Santander del Consejo de Monumentos Nacionales y dio base al informe preparado en mayo de 2009 para los Despachos del señor Gobernador de Santander y de la Secretaría de Desarrollo Departamental. La investigación presenta, por tanto, un recorrido por entidades involucradas en la planificación y manejo del patrimonio cultural inmueble, acciones, proyectos, documentos de ámbito departamental, la legislación vigente sobre el tema, y una revisión a los posibles proyectos que sobre el patrimonio cultural inmueble, pueden adelantarse en el departamento.

\section{PALABRAS CLAVE}

Departamento de Santander, Patrimonio Cultural Inmueble. 


\section{STATUS OF IMMOVABLE CULTURAL HERITAGE IN THE DEPARTMENT OF SANTANDER}

Nahir Pabón Castro*

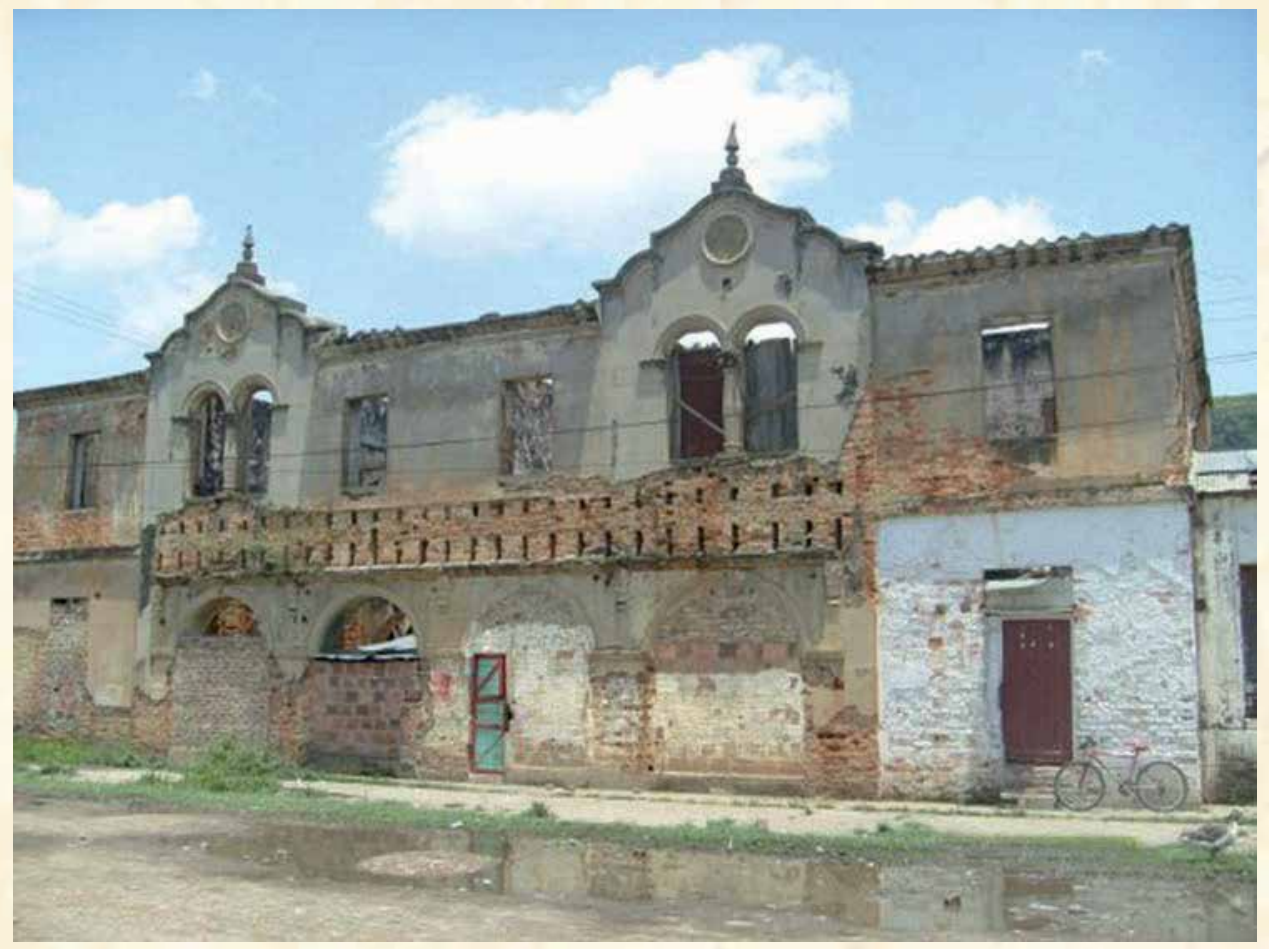

Arquitecta de la Universidad Jorge Tadeo Lozano, Seccional del Caribe, Docente Investigadora en la Facultad de Arquitectura de la Universidad Santo Tomás Bucaramanga. Actualmente adelanta el proyecto de investigación "Seguimiento al Patrimonio Cultural Inmueble en los Planes de Ordenamiento Territorial del Departamento del Santander Estudio de caso: Municipios de la Provincia Guanentina"

Este artículo hace parte del informe preparado en mayo de 2009 para el Despacho del señor Gobernador de Santander y la Secretaría de Desarrollo Departamental
Edificio de la estación de ferrocarril de Barbosa - Santander 2008

Fuente: Archivo del autor

\begin{abstract}
The article belongs to a personal investigation that aimed to follow the subject of Immovable Cultural Heritage in the Department of Santander, starting on the formulation of the General Law of Culture in 1997, as part of the work that was developed by the National Council of Monuments, Branch of Santander, and supported the report prepared in May of 2009 for the Santander Governor's Office and the Secretary of Departmental Development. Thus, this investigation tours around several units involved in the planning and management of immovable cultural heritage, actions, projects, regional documents, the existing legislation on the subject, and a review to some potential projects related to the immovable cultural heritage that could be ahead in the Department of Santander.
\end{abstract}

\title{
KEY WORDS
}

Departament of Santander, Immovable Cultural Heritage 


\section{INTRODUCCIÓN}

Antes de pronunciar cualquier consideración sobre estado del patrimonio cultural inmueble en Santander es necesario puntualizar que la Secretaría de Desarrollo es la dependencia encargada del Patrimonio Cultural en el Departamento, a través de la Coordinación de Cultura y Turismo. Asimismo cabe señalar que la Gobernación contaba con una Oficina encargada del patrimonio, la cual coordinaba las acciones del Centro Filial Santander del Consejo de Monumentos Nacionales y ejercía la Secretaría Técnica del mismo. Esta oficina dependió de la Secretaría de Cultura, Turismo, Recreación y Deporte, hasta la reestructuración de la entidad durante la administración del Dr. Jorge Gómez Villamizar, momento en el que estas funciones se reasignaron a la Secretaría de Desarrollo Social, hoy Secretaría de Desarrollo. Inicia entonces el proceso de decaimiento de la actividad oficial del Departamento en el tema de patrimonio cultural inmueble y por ende una notoria deficiencia en el manejo y administración del tema, provocada por el desconocimiento real del mismo. Además, los exiguos recursos de personal y planta física de la Gobernación, aunados al desconocimiento que muestran los funcionarios sobre la materia, se hacen sentir en esta área con gran fuerza. Esta situación continua durante la administración anterior, ya que los recursos se canalizaron en la creación y refuerzo de la identidad representados en el proyecto del Parque Nacional del Chicamocha.

Al año 2009, el archivo de la Oficina de Patrimonio y del Centro Filial, sigue sin haberse organizado y con toda la documentación repartida en distintas locaciones. Cabe resaltar que reposan en el archivo del Centro Filial Santander del Consejo de Monumentos Nacionales: actas, conceptos, proyectos de intervención y reglamentaciones estudiados con todos sus planos, además de la extensa biblioteca sobre temas de cultura y patrimonio del Departamento. Esta situación continúa a pesar de algunas acciones significativas que se han emprendido, pero que no han servido para promover los procesos que realmente harían de este tema una fortaleza. Las acciones más recientes desarrolladas hasta el momento son:

- Inventario de Patrimonio Cultural Inmueble del Departamento (87 Municipios)

- Inventario de Patrimonio Cultural Inmaterial del Departamento (42 Municipios)

- Conformación del Consejo Departamental de Patrimonio Cultural

Estas acciones pondrían en evidencia cierta sensibilización sobre la importancia del patrimonio cultural inmueble en el departamento, los aspectos del patrimonio cultural mueble, así como los del intangible y del patrimonio natural, pero la realidad es bien distinta, pues todos ellos se encuentran bastante lejos de tener el reconocimiento y apoyo de la administración departamental. Esta afirmación encuentra soporte en una serie de fortalezas y debilidades, traídas a la luz para la formulación del Plan Estratégico de Cultura del Departamento ':

"Patrimonio. La riqueza patrimonial natural y cultural del Departamento es invaluable. El patrimonio natural de Santander, encabezado por el Cañón del Chicamocha, es majestuoso; la diversidad de los paisajes con sus múltiples atributos ha configurado en la última década un desarrollo significativo de la industria turística, perfilando una nueva vocación económica para el territorio.

Sin embargo, el turismo, además de potenciar el desarrollo económico, también ejerce una fuerte presión sobre el patrimonio natural que lo causa, lo que obliga a implementar políticas de protección que permita su explotación en términos

I CENTENO OSMA, Francisco. (Consultor). Departamento de Santander. Plan Estratégico de Cultura "Santander CREA". Bucaramanga, 2009 


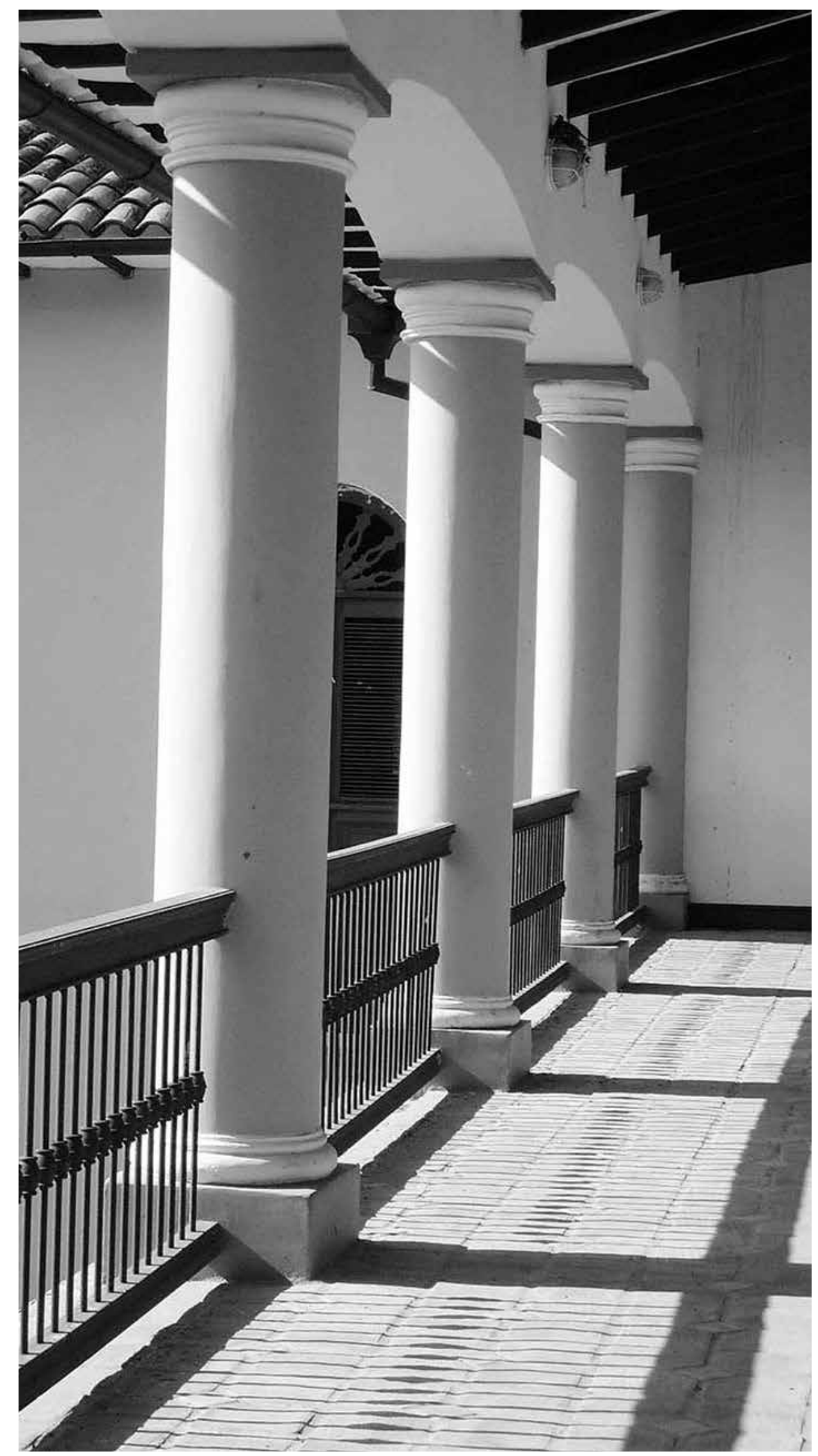

Edificio del Antiguo Colegio del Pilar, hoy Centro Cultural del Oriente. Bucaramanga - 2009 
Edificio de la estación de ferrocarril de Barbosa - Santander - 2008

Fuente: Archivo del autor

Edificio de la estación de ferrocarril de $E$ Guayabo, Puente Nacional - Santander -2008

Fuente: Archivo del autor

Edificio de la estación de ferrocarril de La Capilla, Puente Nacional - Santander - 2008

Fuente: Archivo del autor
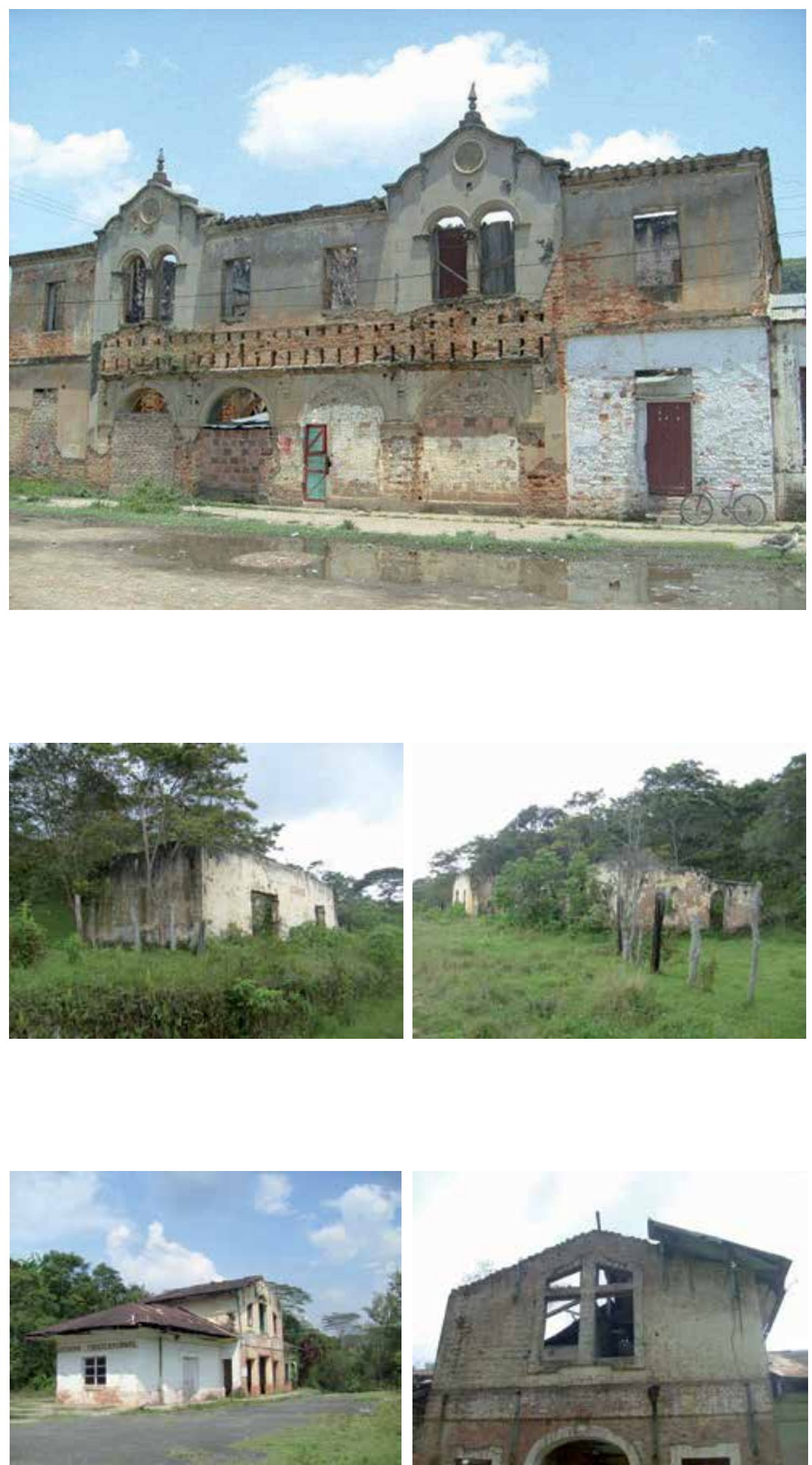
sustentables. La relación inherente entre cultura y territorio conlleva a una relación sinérgica entre cultura y turismo.

No sólo el patrimonio natural es explotable en términos del turismo, también lo es el patrimonio cultural, especialmente el patrimonio histórico. Santander es cuna de las libertades y precursor de los movimientos emancipadores que se dieron en Latinoamérica en el siglo XIX, atributo que no ha sido valorado ni explotado hasta el momento.

El patrimonio inmueble o arquitectónico sigue siendo visto, de manera exclusiva, como objeto de conservación, razón por la que los enfoques de actuación no superan la preservación de fachadas y conjuntos arquitectónicos. El patrimonio cultural inmaterial del Departamento, caracterizado por las formas vivas de la cultura, apenas empieza a inventariarse para su valoración, pero se da por sentada su enorme riqueza. El arte religioso y el patrimonio mueble, bajo custodia de las instituciones religiosas y museos, principalmente, tampoco han sido inventariados, investigados ni declarados.

Muchas de las colecciones arqueológicas de los museos proceden de prácticas de guaquería que anulan el conocimiento de contexto de las piezas y, por ende, el conocimiento a profundidad de las culturas precolombinas que los produjeron. Desde hace décadas, el Departamento abandonó su patrimonio arqueológico y promovió con esto la práctica ilegal de su explotación por parte de los guaqueros.

La Biblioteca Departamental fue cerrada en el año 2000 y sus valiosos contenidos almacenados en cajas sin la más mínima protección. Desde que se cerró, los gobiernos han anunciado su apertura sin que a la fecha se haya materializado.

La formulación de Planes Especiales de Manejo y Protección (PEMP) para el patrimonio inmueble y su adopción por parte de los municipios es de suma urgencia para Santander, ya que se evidencia una fuerte e inconveniente presión, derivada de intereses particulares y la falta de valoración y voluntad política de los gobiernos. Actualmente existen 4 centros históricos declarados patrimonio cultural de orden nacional que están a la espera de la formulación de sus PEMP (Barichara, Girón, Socorro y San Gil); estudios de reglamentación de marcos de plaza para I I municipios y un corregimiento que no han sido adoptados; 34 estaciones de ferrocarril que fueron declaradas por decreto nacional, pero a las que no se les ha hecho la respectiva valoración; los caminos indígenas, reales y de Lenguerke en peligro de desaparición; e innumerables muestras de edilicia desaparecida o amenazada.

El reciente inventario realizado por Corpocides eligió una lista de 140 inmuebles objeto de ser valorados como bienes de interés cultural departamental: provincia de Vélez (32), provincia de Soto (22), provincia de Mares (16), provincia Comunera (25) provincia Guanentina (3I) y provincia de García Rovira (I4).

En el mejor de los casos, los Planes de Ordenamiento Territorial reconocen la presencia del patrimonio cultural inmueble, promueven la preservación de fachadas, pero desatienden el objeto y el conjunto urbano en el que se incluye, desconociendo espacialidades, lenguajes formales, materiales de construcción y centros de manzana. 
Muchas acciones municipales se han ejecutado de manera independiente y descoordinada de las instancias departamentales y nacionales, más basadas en la emocionalidad local que en estudios técnicos, lo que ha permitido declaratorias meramente protocolarias y sin efectos positivos sobre el manejo y protección del bien.

Se percibe en el Departamento un gran déficit de profesionales calificados para el trabajo en el área de patrimonio. Existen dos facultades de arquitectura que no tienen en sus respectivos pensum asignaturas de patrimonio, ni siquiera como electivas complementarias; ingenieros civiles que descalifican la arquitectura tradicional; historiadores y sociólogos enfocados a otras instancias; programas de hotelería y turismo que no dan suficiente valor al patrimonio como insumo económico; escuelas de artes donde apenas si se consideran las manifestaciones tradicionales de la cultura; escuelas de comunicación sin mayor interés por el tema; y ausencia total de programas de formación en gestión de la cultura; lo que pone de presente el, distanciamiento de la academia respecto al tema de patrimonio.

Destacamos el programa de televisión Por los caminos del gran Santander, realizado por el historiador Emilio Arenas con el patrocinio de la Universidad Santo Tomás de Bucaramanga, como uno de los pocos elementos visibles del interés de la academia por el patrimonio y la memoria del Departamento.

A todo esto se suma la poca eficacia y eficiencia de la actuación gubernamental y su incapacidad demostrada para coordinar, articular y gestionar el sector. La lentitud de los trámites y el evidente manejo anti técnico, aunado a los exiguos recursos que se destinan al patrimonio cultural hacen muy difícil su preservación y su refuncionalización como pieza clave del desarrollo social y económico del Departamento.

El desconocimiento de la legislación y la normatividad provoca la descoordinación de los niveles nacional, departamental y municipal, lo que aumenta el riesgo para el patrimonio cultural y limita su aprovechamiento. La ausencia de un sistema de información, documentación y memoria con contenidos sustanciales, organizados y públicamente visibles, y un Consejo Departamental de Patrimonio que apenas se acaba de instalar, son motivos suficientes para que el Plan Estratégico de Cultura subraye acciones efectivas al respecto.

El programa Vigías del patrimonio del Ministerio de Cultura apenas empieza a despegar en Santander, lo que obliga a enfatizar esfuerzos en tal sentido, ampliándolo y consolidándolo mediante procesos de capacitación especializada y trabajo en red dirigidos a la apropiación social del patrimonio y su valoración dentro del nuevo escenario de competitividad económica que se ha trazado para el Departamento."

\section{LA LEGISLACIÓN VIGENTE}

La legislación sobre el patrimonio cultural inmueble es puntual y a pesar de que reglamenta los aspectos de los bienes inmuebles que son de relevancia nacional, deja vacíos en cuanto a los bienes inmuebles de relevancia regional. Esto se refleja en los siguientes instrumentos:

- Constitución Política de Colombia

- $\quad$ Ley 388 de 1997, Ley de Ordenamiento Territorial 
- Ley 397 de 1997, Ley General de Cultura

- Ley I 85 de 2008, Modificatoria de la Ley General de Cultura

- Decreto 13/3 de 2008, Reglamentario de la Ley II 85 de 2008

- Decreto 763 de 2009, Reglamentario de la Ley II 85 de 2008

En cuanto al patrimonio cultural inmueble, debe tenerse en cuenta, que la Ley 388 de 1997, establece que el Patrimonio Cultural es una determinante que constituye norma de superior jerarquía, en sus propios ámbitos de competencia, de acuerdo con la Constitución y las leyes ${ }^{2}$. A pesar de esto, el resto de la legislación concerniente a Patrimonio y Cultura, se anexa como listado y copia de las mismas en el medio magnético.

\section{LOS BIENES DE INTERÉS CULTURAL DEL DEPARTAMENTO}

Conforman la lista de Bienes de Interés Cultural de ámbito Nacional del Departamento 3 (antiguamente Monumentos Nacionales) 52 Bienes distribuidos de la siguiente manera: (4) Centros Históricos, (6) Edificaciones, (4) Iglesias, (34) Estaciones de Ferrocarril, (I) Camino Real, (I) Puente (Ver cuadro I.)

Cuadro I. Listado de Bienes de Interés Cultural del Departamento de Santander

\begin{tabular}{|c|c|c|c|c|c|}
\hline MUNICIPIO & $\begin{array}{l}\text { NOMBRE } \\
\text { DEL BIEN }\end{array}$ & $\begin{array}{l}\text { NIVEL DE DE- } \\
\text { CLARATORIA }\end{array}$ & $\begin{array}{l}\text { ACTO } \\
\text { ADMINIS- } \\
\text { TRATIVO } \\
\text { PROPONE }\end{array}$ & $\begin{array}{l}\text { ACTO } \\
\text { ADMINIS- } \\
\text { TRATIVO } \\
\text { DECLARA }\end{array}$ & OBSERVACIONES \\
\hline BARBOSA & $\begin{array}{l}\text { Estación del } \\
\text { Ferrocarril } \\
\text { Barbosa }\end{array}$ & $\begin{array}{l}\text { Monumento } \\
\text { Nacional (D) }\end{array}$ & $\begin{array}{l}\text { Resolución } \\
013 \text { I6-VIII- } \\
1994 \text { (Pro- } \\
\text { pone) }\end{array}$ & $\begin{array}{l}\text { Decreto } 746 \\
\text { 24-IV-I996 } \\
\text { (Declara) }\end{array}$ & $\begin{array}{l}\text { Pertenece al Conjunto } \\
\text { Patrimonial de orden Na- } \\
\text { cional de las Estaciones de } \\
\text { Pasajeros del Ferrocarril en } \\
\text { Colombia. Siglo XIX - XX }\end{array}$ \\
\hline BARICHARA & $\begin{array}{l}\text { Sector } \\
\text { Antiguo del } \\
\text { Municipio de } \\
\text { Barichara }\end{array}$ & $\begin{array}{l}\text { Monumento } \\
\text { Nacional (D) }\end{array}$ & & $\begin{array}{l}\text { Decreto I654 } \\
\text { 3-VIII-I978 } \\
\text { (Declara) }\end{array}$ & \\
\hline $\begin{array}{l}\text { BARICHARA } \\
\text { GUANE }\end{array}$ & $\begin{array}{l}\text { Camino Real } \\
\text { de Barichara } \\
\text { a Guane }\end{array}$ & $\begin{array}{l}\text { Bien de Interés } \\
\text { Cultural de } \mathrm{Ca} \text { - } \\
\text { rácter Nacional }\end{array}$ & $\begin{array}{l}\text { Resolución } \\
0206 \text { 6-VIII- } \\
\text { I997 (Pro- } \\
\text { pone) }\end{array}$ & $\begin{array}{l}\text { Resolución } \\
0790 \text { 3I-VII- } \\
\text { I998 (Declara) }\end{array}$ & $\begin{array}{l}\text { Forma parte de la Red de } \\
\text { Caminos Reales que vin- } \\
\text { culaban el centro - oriente } \\
\text { colombiano. }\end{array}$ \\
\hline $\begin{array}{l}\text { BARICHARA } \\
\text { GUANE }\end{array}$ & $\begin{array}{l}\text { Iglesia Parro- } \\
\text { quial de Santa } \\
\text { Lucía }\end{array}$ & $\begin{array}{l}\text { Bien de Interés } \\
\text { Cultural de } \mathrm{Ca}- \\
\text { rácter Nacional }\end{array}$ & $\begin{array}{l}\text { Resolución } \\
\text { 0II 24-VII- } \\
\text { I997 (Pro- } \\
\text { pone) }\end{array}$ & $\begin{array}{l}\text { Resolución } \\
0795 \text { 3I-VII- } \\
\text { I998 (Declara) }\end{array}$ & \\
\hline $\begin{array}{l}\text { BARRANCABER- } \\
\text { MEJA }\end{array}$ & $\begin{array}{c}\text { Estación del } \\
\text { Ferrocarril } \\
\text { Barrancaber- } \\
\text { meja }\end{array}$ & $\begin{array}{l}\text { Monumento } \\
\text { Nacional (D) }\end{array}$ & $\begin{array}{l}\text { Resolución } \\
013 \text { I6-VIII- } \\
\text { I994 (Pro- } \\
\text { pone) }\end{array}$ & $\begin{array}{l}\text { Decreto } 746 \\
\text { 24-IV-I996 } \\
\text { (Declara) }\end{array}$ & $\begin{array}{l}\text { Pertenece al Conjunto } \\
\text { Patrimonial de orden Na- } \\
\text { cional de las Estaciones de } \\
\text { Pasajeros del Ferrocarril en } \\
\text { Colombia. Siglo XIX - XX }\end{array}$ \\
\hline $\begin{array}{c}\text { BARRANCABER- } \\
\text { MEJA }\end{array}$ & $\begin{array}{l}\text { Estación del } \\
\text { Ferrocarril } \\
\text { Cuatrobocas }\end{array}$ & $\begin{array}{l}\text { Monumento } \\
\text { Nacional (D) }\end{array}$ & $\begin{array}{l}\text { Resolución } \\
013 \text { I6-VIII- } \\
\text { I994 (Pro- } \\
\text { pone) }\end{array}$ & $\begin{array}{l}\text { Decreto } 746 \\
24-I V-1996 \\
\text { (Declara) }\end{array}$ & $\begin{array}{l}\text { Pertenece al Conjunto } \\
\text { Patrimonial de orden Na- } \\
\text { cional de las Estaciones de } \\
\text { Pasajeros del Ferrocarril en } \\
\text { Colombia. Siglo XIX - XX }\end{array}$ \\
\hline $\begin{array}{c}\text { BARRANCABER- } \\
\text { MEJA }\end{array}$ & $\begin{array}{l}\text { Estación del } \\
\text { Ferrocarril } \\
\text { Pénjamo }\end{array}$ & $\begin{array}{l}\text { Monumento } \\
\text { Nacional (D) }\end{array}$ & $\begin{array}{c}\text { Resolución } \\
\text { 013 I6-VIII- } \\
\text { I994 (Pro- } \\
\text { pone) }\end{array}$ & $\begin{array}{c}\text { Decreto } 746 \\
\text { 24-IV-I996 } \\
\text { (Declara) }\end{array}$ & $\begin{array}{l}\text { Pertenece al Conjunto } \\
\text { Patrimonial de orden Na- } \\
\text { cional de las Estaciones de } \\
\text { Pasajeros del Ferrocarril en } \\
\text { Colombia. Siglo XIX - XX }\end{array}$ \\
\hline
\end{tabular}

2 República de Colombia. Ley 388 de 1997. Artículo 10, Numeral 2

3 Información disponible en www.mincultura.gov.co. Consulta realizada el 30 de agosto de 2008 


\begin{tabular}{|c|c|c|c|c|c|}
\hline BUCARAMANGA & $\begin{array}{l}\text { Capilla de } \\
\text { Los Dolores }\end{array}$ & $\begin{array}{l}\text { Monumento } \\
\text { Nacional (D) }\end{array}$ & & $\begin{array}{l}\text { Decreto } 2210 \\
2 \mid-V I I-1954 \\
\text { (Declara) }\end{array}$ & \\
\hline BUCARAMANGA & $\begin{array}{l}\text { Casa de } \\
\text { Bolívar }\end{array}$ & $\begin{array}{l}\text { Bien de Interés } \\
\text { Cultural de Ca- } \\
\text { rácter Nacional }\end{array}$ & & $\begin{array}{l}\text { Resolución } \\
\text { I613 26-XI- } \\
\text { I999 (Declara) }\end{array}$ & $\begin{array}{c}\text { Actual sede de la Academia } \\
\text { de Historia de Santander } \\
\text { y del Museo Histórico y } \\
\text { Antropológico }\end{array}$ \\
\hline BUCARAMANGA & $\begin{array}{c}\text { Casa natal } \\
\text { de Custodio } \\
\text { García Rovira }\end{array}$ & $\begin{array}{l}\text { Monumento } \\
\text { Nacional (D) }\end{array}$ & & $\begin{array}{l}\text { Ley } 48 \text { I-IX- } \\
\text { I } 966 \text { (Declara) }\end{array}$ & \\
\hline BUCARAMANGA & $\begin{array}{l}\text { Colegio de } \\
\text { Nuestra } \\
\text { Señora del } \\
\text { Pilar }\end{array}$ & $\begin{array}{l}\text { Monumento } \\
\text { Nacional (D) }\end{array}$ & $\begin{array}{l}\text { Resolución } \\
007 \text { I6-VIII- } \\
\text { I994 (Pro- } \\
\text { pone) }\end{array}$ & $\begin{array}{l}\text { Decreto } 1910 \\
2-X I-1995 \\
\text { (Declara) }\end{array}$ & \\
\hline BUCARAMANGA & $\begin{array}{l}\text { Coliseo } \\
\text { Peralta }\end{array}$ & $\begin{array}{l}\text { Monumento } \\
\text { Nacional (D) }\end{array}$ & $\begin{array}{c}\text { Resolución } 06 \\
26-X 1-1974 \\
\text { (Propone) }\end{array}$ & $\begin{array}{l}\text { Decreto } 292 \\
24-I 1-1975 \\
\text { (Declara) }\end{array}$ & \\
\hline $\begin{array}{l}\text { BUCARAMANGA. } \\
\text { ESTACIÓN MA- } \\
\text { DRID }\end{array}$ & $\begin{array}{l}\text { Estación del } \\
\text { Ferrocarril } \\
\text { Café Madrid }\end{array}$ & $\begin{array}{l}\text { Monumento } \\
\text { Nacional (D) }\end{array}$ & $\begin{array}{l}\text { Resolución } \\
013 \text { I6-VIII- } \\
\text { I994 (Pro- } \\
\text { pone) }\end{array}$ & $\begin{array}{l}\text { Decreto } 746 \\
24-I V-1996 \\
\text { (Declara) }\end{array}$ & $\begin{array}{l}\text { Pertenece al Conjunto } \\
\text { Patrimonial de orden } \mathrm{Na} \text { - } \\
\text { cional de las Estaciones de } \\
\text { Pasajeros del Ferrocarril en } \\
\text { Colombia. Siglo XIX - XX }\end{array}$ \\
\hline CIMITARRA & $\begin{array}{l}\text { Estación del } \\
\text { Ferrocarril } \\
\text { Carare }\end{array}$ & $\begin{array}{l}\text { Monumento } \\
\text { Nacional (D) }\end{array}$ & $\begin{array}{l}\text { Resolución } \\
013 \text { 16-VIII- } \\
\text { I } 994 \text { (Pro- } \\
\text { pone) }\end{array}$ & $\begin{array}{l}\text { Decreto } 746 \\
24-I V-1996 \\
\text { (Declara) }\end{array}$ & $\begin{array}{l}\text { Pertenece al Conjunto } \\
\text { Patrimonial de orden } \mathrm{Na} \text { - } \\
\text { cional de las Estaciones de } \\
\text { Pasajeros del Ferrocarril en } \\
\text { Colombia. Siglo XIX - XX }\end{array}$ \\
\hline CIMITARRA & $\begin{array}{l}\text { Estación del } \\
\text { Ferrocarril } \\
\text { San Juan }\end{array}$ & $\begin{array}{l}\text { Monumento } \\
\text { Nacional (D) }\end{array}$ & $\begin{array}{l}\text { Resolución } \\
013 \text { I6-VIII- } \\
\text { I994 (Pro- } \\
\text { pone) }\end{array}$ & $\begin{array}{l}\text { Decreto } 746 \\
24-I V-1996 \\
\text { (Declara) }\end{array}$ & $\begin{array}{l}\text { Pertenece al Conjunto } \\
\text { Patrimonial de orden } \mathrm{Na}- \\
\text { cional de las Estaciones de } \\
\text { Pasajeros del Ferrocarril en } \\
\text { Colombia. Siglo XIX - XX }\end{array}$ \\
\hline $\begin{array}{l}\text { CIMITARRA. } \\
\text { PUERTO OLAYA }\end{array}$ & $\begin{array}{l}\text { Estación del } \\
\text { Ferrocarril } \\
\text { Puerto Olaya }\end{array}$ & $\begin{array}{l}\text { Monumento } \\
\text { Nacional (D) }\end{array}$ & $\begin{array}{l}\text { Resolución } \\
013 \text { I6-VIII- } \\
\text { I994 (Pro- } \\
\text { pone) }\end{array}$ & $\begin{array}{l}\text { Decreto } 746 \\
24-I V-1996 \\
\text { (Declara) }\end{array}$ & $\begin{array}{l}\text { Pertenece al Conjunto } \\
\text { Patrimonial de orden } \mathrm{Na} \text { - } \\
\text { cional de las Estaciones de } \\
\text { Pasajeros del Ferrocarril en } \\
\text { Colombia. Siglo XIX - XX }\end{array}$ \\
\hline CONFINES & $\begin{array}{l}\text { Iglesia de San } \\
\text { Cayetano }\end{array}$ & $\begin{array}{l}\text { Monumento } \\
\text { Nacional (D) }\end{array}$ & & $\begin{array}{c}\text { Decreto II } 92 \\
26-V-1977 \\
\text { (Declara) }\end{array}$ & \\
\hline GIRÓN & $\begin{array}{l}\text { Estación del } \\
\text { Ferrocarril } \\
\text { Palmas }\end{array}$ & $\begin{array}{l}\text { Monumento } \\
\text { Nacional (D) }\end{array}$ & $\begin{array}{c}\text { Resolución } \\
013 \text { I6-VIII- } \\
\text { I994 (Pro- } \\
\text { pone) }\end{array}$ & $\begin{array}{c}\text { Decreto } 746 \\
24-I V-1996 \\
\text { (Declara) }\end{array}$ & $\begin{array}{l}\text { Pertenece al Conjunto } \\
\text { Patrimonial de orden } \mathrm{Na} \text { - } \\
\text { cional de las Estaciones de } \\
\text { Pasajeros del Ferrocarril en } \\
\text { Colombia. Siglo XIX - XX }\end{array}$ \\
\hline GIRÓN & $\begin{array}{c}\text { Sector } \\
\text { Antiguo de } \\
\text { la Ciudad de } \\
\text { Girón }\end{array}$ & $\begin{array}{l}\text { Monumento } \\
\text { Nacional (D) }\end{array}$ & & $\begin{array}{c}\text { Decreto } 264 \\
\text { I2-II-I963 } \\
\text { (Declara) }\end{array}$ & Sector Urbano Delimitado \\
\hline LEBRIJA & $\begin{array}{c}\text { Estación del } \\
\text { Ferrocarril } \\
\text { Puerto } \\
\text { Santos }\end{array}$ & $\begin{array}{l}\text { Monumento } \\
\text { Nacional (D) }\end{array}$ & $\begin{array}{c}\text { Resolución } \\
013 \text { I6-VIII- } \\
\text { I } 994 \text { (Pro- } \\
\text { pone) }\end{array}$ & $\begin{array}{c}\text { Decreto } 746 \\
24-I V-1996 \\
\text { (Declara) }\end{array}$ & $\begin{array}{l}\text { Pertenece al Conjunto } \\
\text { Patrimonial de orden Na- } \\
\text { cional de las Estaciones de } \\
\text { Pasajeros del Ferrocarril en } \\
\text { Colombia. Siglo XIX - XX }\end{array}$ \\
\hline LEBRIJA. CHUSPAS & $\begin{array}{c}\text { Estación del } \\
\text { Ferrocarril } \\
\text { Chuspas }\end{array}$ & $\begin{array}{l}\text { Monumento } \\
\text { Nacional (D) }\end{array}$ & $\begin{array}{c}\text { Resolución } \\
013 \text { I6-VIII- } \\
\text { I } 994 \text { (Pro- } \\
\text { pone) }\end{array}$ & $\begin{array}{c}\text { Decreto } 746 \\
\text { 24-IV-I996 } \\
\text { (Declara) }\end{array}$ & $\begin{array}{l}\text { Pertenece al Conjunto } \\
\text { Patrimonial de orden Na- } \\
\text { cional de las Estaciones de } \\
\text { Pasajeros del Ferrocarril en } \\
\text { Colombia. Siglo XIX - XX }\end{array}$ \\
\hline $\begin{array}{l}\text { LEBRIJA. } \\
\text { CONCHAL }\end{array}$ & $\begin{array}{l}\text { Estación del } \\
\text { Ferrocarril } \\
\text { Conchal }\end{array}$ & $\begin{array}{l}\text { Monumento } \\
\text { Nacional (D) }\end{array}$ & $\begin{array}{c}\text { Resolución } \\
013 \text { I6-VIII- } \\
\text { I994 (Pro- } \\
\text { pone) }\end{array}$ & $\begin{array}{c}\text { Decreto } 746 \\
24-I V-1996 \\
\text { (Declara) }\end{array}$ & $\begin{array}{l}\text { Pertenece al Conjunto } \\
\text { Patrimonial de orden Na- } \\
\text { cional de las Estaciones de } \\
\text { Pasajeros del Ferrocarril en } \\
\text { Colombia. Siglo XIX - XX }\end{array}$ \\
\hline LEBRIJA. VANEGAS & $\begin{array}{c}\text { Estación del } \\
\text { Ferrocarril } \\
\text { Vanegas }\end{array}$ & $\begin{array}{l}\text { Monumento } \\
\text { Nacional (D) }\end{array}$ & $\begin{array}{c}\text { Resolución } \\
013 \text { I6-VIII- } \\
\text { I994 (Pro- } \\
\text { pone) }\end{array}$ & $\begin{array}{c}\text { Decreto } 746 \\
24-I V-1996 \\
\text { (Declara) }\end{array}$ & $\begin{array}{l}\text { Pertenece al Conjunto } \\
\text { Patrimonial de orden Na- } \\
\text { cional de las Estaciones de } \\
\text { Pasajeros del Ferrocarril en } \\
\text { Colombia. Siglo XIX - XX }\end{array}$ \\
\hline
\end{tabular}




\begin{tabular}{|c|c|c|c|c|c|}
\hline MATANZA & $\begin{array}{c}\text { Iglesia de } \\
\text { Matanza y su } \\
\text { colección de } \\
\text { Obra Mueble }\end{array}$ & $\begin{array}{l}\text { Bien de Interés } \\
\text { Cultural de Ca- } \\
\text { rácter Nacional }\end{array}$ & & $\begin{array}{c}\text { Resolución } \\
\text { I873 28-XII- } \\
2000 \text { (Declara) }\end{array}$ & $\begin{array}{l}\text { Posee Colección de Obra } \\
\text { Mueble }\end{array}$ \\
\hline $\begin{array}{l}\text { PUENTE } \\
\text { NACIONAL }\end{array}$ & $\begin{array}{l}\text { Estación del } \\
\text { Ferrocarril } \\
\text { Guayabo }\end{array}$ & $\begin{array}{l}\text { Monumento } \\
\text { Nacional (D) }\end{array}$ & $\begin{array}{l}\text { Resolución } \\
013 \text { I6-VIII- } \\
\text { I994 (Pro- } \\
\text { pone) }\end{array}$ & $\begin{array}{c}\text { Decreto } 746 \\
24-I V-1996 \\
\text { (Declara) }\end{array}$ & $\begin{array}{l}\text { Pertenece al Conjunto } \\
\text { Patrimonial de orden Na- } \\
\text { cional de las Estaciones de } \\
\text { Pasajeros del Ferrocarril en } \\
\text { Colombia. Siglo XIX - XX }\end{array}$ \\
\hline $\begin{array}{c}\text { PUENTE } \\
\text { NACIONAL }\end{array}$ & $\begin{array}{l}\text { Estación del } \\
\text { Ferrocarril } \\
\text { Límites }\end{array}$ & $\begin{array}{l}\text { Monumento } \\
\text { Nacional (D) }\end{array}$ & $\begin{array}{l}\text { Resolución } \\
013 \text { I6-VIII- } \\
1994 \text { (Pro- } \\
\text { pone) }\end{array}$ & $\begin{array}{c}\text { Decreto } 746 \\
24-I V-1996 \\
\text { (Declara) }\end{array}$ & $\begin{array}{l}\text { Pertenece al Conjunto } \\
\text { Patrimonial de orden Na- } \\
\text { cional de las Estaciones de } \\
\text { Pasajeros del Ferrocarril en } \\
\text { Colombia. Siglo XIX - XX }\end{array}$ \\
\hline $\begin{array}{c}\text { PUENTE } \\
\text { NACIONAL. LOS } \\
\text { ROBLES }\end{array}$ & $\begin{array}{l}\text { Estación del } \\
\text { Ferrocarril } \\
\text { Los Robles }\end{array}$ & $\begin{array}{l}\text { Monumento } \\
\text { Nacional (D) }\end{array}$ & $\begin{array}{l}\text { Resolución } \\
013 \text { I6-VIII- } \\
\text { I994 (Pro- } \\
\text { pone) }\end{array}$ & $\begin{array}{c}\text { Decreto } 746 \\
24-I V-1996 \\
\text { (Declara) }\end{array}$ & $\begin{array}{l}\text { Pertenece al Conjunto } \\
\text { Patrimonial de orden Na- } \\
\text { cional de las Estaciones de } \\
\text { Pasajeros del Ferrocarril en } \\
\text { Colombia. Siglo XIX - XX }\end{array}$ \\
\hline $\begin{array}{c}\text { PUENTE } \\
\text { NACIONAL. } \\
\text { PROVIDENCIA }\end{array}$ & $\begin{array}{l}\text { Estación del } \\
\text { Ferrocarril } \\
\text { Providencia }\end{array}$ & $\begin{array}{l}\text { Monumento } \\
\text { Nacional (D) }\end{array}$ & $\begin{array}{l}\text { Resolución } \\
013 \text { I6-VIII- } \\
\text { I994 (Pro- } \\
\text { pone) }\end{array}$ & $\begin{array}{c}\text { Decreto } 746 \\
24-I V-1996 \\
\text { (Declara) }\end{array}$ & $\begin{array}{l}\text { Pertenece al Conjunto } \\
\text { Patrimonial de orden Na- } \\
\text { cional de las Estaciones de } \\
\text { Pasajeros del Ferrocarril en } \\
\text { Colombia. Siglo XIX - XX }\end{array}$ \\
\hline $\begin{array}{l}\text { PUERTO } \\
\text { WILCHES }\end{array}$ & $\begin{array}{l}\text { Estación del } \\
\text { Ferrocarril El } \\
\text { Cruce }\end{array}$ & $\begin{array}{l}\text { Monumento } \\
\text { Nacional (D) }\end{array}$ & $\begin{array}{l}\text { Resolución } \\
013 \text { I6-VIII- } \\
\text { I994 (Pro- } \\
\text { pone) }\end{array}$ & $\begin{array}{l}\text { Decreto } 746 \\
24-I V-1996 \\
\text { (Declara) }\end{array}$ & $\begin{array}{l}\text { Pertenece al Conjunto } \\
\text { Patrimonial de orden Na- } \\
\text { cional de las Estaciones de } \\
\text { Pasajeros del Ferrocarril en } \\
\text { Colombia. Siglo XIX - XX }\end{array}$ \\
\hline $\begin{array}{l}\text { PUERTO } \\
\text { WILCHES }\end{array}$ & $\begin{array}{l}\text { Estación del } \\
\text { Ferrocarril } \\
\text { García } \\
\text { Cadena }\end{array}$ & $\begin{array}{l}\text { Monumento } \\
\text { Nacional (D) }\end{array}$ & $\begin{array}{l}\text { Resolución } \\
013 \text { 16-VIII- } \\
\text { I994 (Pro- } \\
\text { pone) }\end{array}$ & $\begin{array}{c}\text { Decreto } 746 \\
24-I V-1996 \\
\text { (Declara) }\end{array}$ & $\begin{array}{l}\text { Pertenece al Conjunto } \\
\text { Patrimonial de orden Na- } \\
\text { cional de las Estaciones de } \\
\text { Pasajeros del Ferrocarril en } \\
\text { Colombia. Siglo XIX - XX }\end{array}$ \\
\hline $\begin{array}{l}\text { PUERTO } \\
\text { WILCHES }\end{array}$ & $\begin{array}{l}\text { Estación del } \\
\text { Ferrocarril } \\
\text { González } \\
\text { Vásquez }\end{array}$ & $\begin{array}{l}\text { Monumento } \\
\text { Nacional (D) }\end{array}$ & $\begin{array}{l}\text { Resolución } \\
013 \text { I6-VIII- } \\
\text { I994 (Pro- } \\
\text { pone) }\end{array}$ & $\begin{array}{l}\text { Decreto } 746 \\
24-I V-1996 \\
\text { (Declara) }\end{array}$ & $\begin{array}{l}\text { Pertenece al Conjunto } \\
\text { Patrimonial de orden Na- } \\
\text { cional de las Estaciones de } \\
\text { Pasajeros del Ferrocarril en } \\
\text { Colombia. Siglo XIX - XX }\end{array}$ \\
\hline $\begin{array}{l}\text { PUERTO } \\
\text { WILCHES }\end{array}$ & $\begin{array}{l}\text { Estación del } \\
\text { Ferrocarril } \\
\text { Puerto } \\
\text { Wilches }\end{array}$ & $\begin{array}{l}\text { Monumento } \\
\text { Nacional (D) }\end{array}$ & $\begin{array}{l}\text { Resolución } \\
013 \text { I6-VIII- } \\
\text { I994 (Pro- } \\
\text { pone) }\end{array}$ & $\begin{array}{l}\text { Decreto } 746 \\
24-I V-1996 \\
\text { (Declara) }\end{array}$ & $\begin{array}{l}\text { Pertenece al Conjunto } \\
\text { Patrimonial de orden Na- } \\
\text { cional de las Estaciones de } \\
\text { Pasajeros del Ferrocarril en } \\
\text { Colombia. Siglo XIX - XX }\end{array}$ \\
\hline $\begin{array}{l}\text { PUERTO } \\
\text { WILCHES. } \\
\text { PUENTE } \\
\text { SOGAMOSO }\end{array}$ & $\begin{array}{l}\text { Estación del } \\
\text { Ferrocarril } \\
\text { Sogamoso }\end{array}$ & $\begin{array}{l}\text { Monumento } \\
\text { Nacional (D) }\end{array}$ & $\begin{array}{l}\text { Resolución } \\
013 \text { 16-VIII- } \\
\text { I994 (Pro- } \\
\text { pone) }\end{array}$ & $\begin{array}{c}\text { Decreto } 746 \\
24-I V-1996 \\
\text { (Declara) }\end{array}$ & $\begin{array}{l}\text { Pertenece al Conjunto } \\
\text { Patrimonial de orden } \mathrm{Na} \text { - } \\
\text { cional de las Estaciones de } \\
\text { Pasajeros del Ferrocarril en } \\
\text { Colombia. Siglo XIX - XX }\end{array}$ \\
\hline RIONEGRO & $\begin{array}{c}\text { Estación del } \\
\text { Ferrocarril } \\
\text { Lebrija }\end{array}$ & $\begin{array}{l}\text { Monumento } \\
\text { Nacional (D) }\end{array}$ & $\begin{array}{c}\text { Resolución } \\
013 \text { I6-VIII- } \\
\text { I994 (Pro- } \\
\text { pone) }\end{array}$ & $\begin{array}{c}\text { Decreto } 746 \\
\text { 24-IV-1996 } \\
\text { (Declara) }\end{array}$ & $\begin{array}{l}\text { Pertenece al Conjunto } \\
\text { Patrimonial de orden Na- } \\
\text { cional de las Estaciones de } \\
\text { Pasajeros del Ferrocarril en } \\
\text { Colombia. Siglo XIX - XX }\end{array}$ \\
\hline $\begin{array}{l}\text { SABANA DE } \\
\text { TORRES }\end{array}$ & $\begin{array}{l}\text { Estación del } \\
\text { Ferrocarril } \\
\text { Celestino } \\
\text { Mutis }\end{array}$ & $\begin{array}{l}\text { Monumento } \\
\text { Nacional (D) }\end{array}$ & $\begin{array}{c}\text { Resolución } \\
013 \text { I6-VIII- } \\
\text { I994 (Pro- } \\
\text { pone) }\end{array}$ & $\begin{array}{c}\text { Decreto } 746 \\
24-I V-1996 \\
\text { (Declara) }\end{array}$ & $\begin{array}{l}\text { Pertenece al Conjunto } \\
\text { Patrimonial de orden Na- } \\
\text { cional de las Estaciones de } \\
\text { Pasajeros del Ferrocarril en } \\
\text { Colombia. Siglo XIX - XX }\end{array}$ \\
\hline $\begin{array}{l}\text { SABANA DE } \\
\text { TORRES }\end{array}$ & $\begin{array}{l}\text { Estación del } \\
\text { Ferrocarril } \\
\text { Comuneros }\end{array}$ & $\begin{array}{l}\text { Monumento } \\
\text { Nacional (D) }\end{array}$ & $\begin{array}{c}\text { Resolución } \\
013 \text { I6-VIII- } \\
\text { I994 (Pro- } \\
\text { pone) }\end{array}$ & $\begin{array}{c}\text { Decreto } 746 \\
24-I V-1996 \\
\text { (Declara) }\end{array}$ & $\begin{array}{l}\text { Pertenece al Conjunto } \\
\text { Patrimonial de orden } \mathrm{Na} \text { - } \\
\text { cional de las Estaciones de } \\
\text { Pasajeros del Ferrocarril en } \\
\text { Colombia. Siglo XIX - XX }\end{array}$ \\
\hline $\begin{array}{l}\text { SABANA DE } \\
\text { TORRES }\end{array}$ & $\begin{array}{c}\text { Estación del } \\
\text { Ferrocarril } \\
\text { Eloy Valen- } \\
\text { zuela }\end{array}$ & $\begin{array}{l}\text { Monumento } \\
\text { Nacional (D) }\end{array}$ & $\begin{array}{c}\text { Resolución } \\
013 \text { I6-VIII- } \\
\text { I994 (Pro- } \\
\text { pone) }\end{array}$ & $\begin{array}{c}\text { Decreto } 746 \\
\text { 24-IV-1996 } \\
\text { (Declara) }\end{array}$ & $\begin{array}{l}\text { Pertenece al Conjunto } \\
\text { Patrimonial de orden Na- } \\
\text { cional de las Estaciones de } \\
\text { Pasajeros del Ferrocarril en } \\
\text { Colombia. Siglo XIX - XX }\end{array}$ \\
\hline
\end{tabular}




\begin{tabular}{|c|c|c|c|c|c|}
\hline $\begin{array}{l}\text { SABANA DE } \\
\text { TORRES. } \\
\text { PROVINCIA }\end{array}$ & $\begin{array}{c}\text { Estación del } \\
\text { Ferrocarril } \\
\text { Provincia }\end{array}$ & $\begin{array}{l}\text { Monumento } \\
\text { Nacional (D) }\end{array}$ & $\begin{array}{c}\text { Resolución } \\
013 \text { I6-VIII- } \\
1994 \text { (Pro- } \\
\text { pone) }\end{array}$ & $\begin{array}{c}\text { Decreto } 746 \\
\text { 24-IV-I996 } \\
\text { (Declara) }\end{array}$ & $\begin{array}{l}\text { Pertenece al Conjunto } \\
\text { Patrimonial de orden } \mathrm{Na} \text { - } \\
\text { cional de las Estaciones de } \\
\text { Pasajeros del Ferrocarril en } \\
\text { Colombia. Siglo XIX - XX }\end{array}$ \\
\hline $\begin{array}{l}\text { SABANA DE } \\
\text { TORRES. } \\
\text { PROVINCIA }\end{array}$ & $\begin{array}{c}\text { Estación del } \\
\text { Ferrocarril } \\
\text { Sabana de } \\
\text { Torres }\end{array}$ & $\begin{array}{l}\text { Monumento } \\
\text { Nacional (D) }\end{array}$ & $\begin{array}{c}\text { Resolución } \\
013 \text { I6-VIII- } \\
1994 \text { (Pro- } \\
\text { pone) }\end{array}$ & $\begin{array}{c}\text { Decreto } 746 \\
\text { 24-IV-1996 } \\
\text { (Declara) }\end{array}$ & $\begin{array}{l}\text { Pertenece al Conjunto } \\
\text { Patrimonial de orden Na- } \\
\text { cional de las Estaciones de } \\
\text { Pasajeros del Ferrocarril en } \\
\text { Colombia. Siglo XIX - XX }\end{array}$ \\
\hline $\begin{array}{l}\text { SABANA DE } \\
\text { TORRES. } \\
\text { SABANETA }\end{array}$ & $\begin{array}{c}\text { Estación del } \\
\text { Ferrocarril } \\
\text { Sabaneta }\end{array}$ & $\begin{array}{l}\text { Monumento } \\
\text { Nacional (D) }\end{array}$ & $\begin{array}{c}\text { Resolución } \\
013 \text { I6-VIII- } \\
1994 \text { (Pro- } \\
\text { pone) }\end{array}$ & $\begin{array}{c}\text { Decreto } 746 \\
\text { 24-IV-I996 } \\
\text { (Declara) }\end{array}$ & $\begin{array}{l}\text { Pertenece al Conjunto } \\
\text { Patrimonial de orden } \mathrm{Na} \text { - } \\
\text { cional de las Estaciones de } \\
\text { Pasajeros del Ferrocarril en } \\
\text { Colombia. Siglo XIX - XX }\end{array}$ \\
\hline SAN GIL & $\begin{array}{l}\text { Colegio } \\
\text { Universitario } \\
\text { San José y } \\
\text { San Pedro de } \\
\text { Alcántara de } \\
\text { Guanentá }\end{array}$ & $\begin{array}{l}\text { Monumento } \\
\text { Nacional (D) }\end{array}$ & $\begin{array}{c}\text { Resolución } \\
00922-X 1- \\
1983 \text { (Pro- } \\
\text { pone) }\end{array}$ & $\begin{array}{c}\text { Decreto } 2862 \\
\text { 26-XI- I984 } \\
\text { (Declara) }\end{array}$ & \\
\hline SAN GIL & $\begin{array}{c}\text { Sector } \\
\text { Antiguo de } \\
\text { la Ciudad de } \\
\text { San Gil }\end{array}$ & $\begin{array}{l}\text { Monumento } \\
\text { Nacional (D) }\end{array}$ & & $\begin{array}{c}\text { Decreto } 264 \\
\text { I2-II-I963 } \\
\text { (Declara) }\end{array}$ & Sector Urbano Delimitado \\
\hline SIMACOTA & $\begin{array}{c}\text { Estación del } \\
\text { Ferrocarril } \\
\text { Opón }\end{array}$ & $\begin{array}{l}\text { Monumento } \\
\text { Nacional (D) }\end{array}$ & $\begin{array}{c}\text { Resolución } \\
013 \text { I6-VIII- } \\
1994 \text { (Pro- } \\
\text { pone) }\end{array}$ & $\begin{array}{c}\text { Decreto } 746 \\
\text { 24-IV-I996 } \\
\text { (Declara) }\end{array}$ & $\begin{array}{l}\text { Pertenece al Conjunto } \\
\text { Patrimonial de orden Na- } \\
\text { cional de las Estaciones de } \\
\text { Pasajeros del Ferrocarril en } \\
\text { Colombia. Siglo XIX - XX }\end{array}$ \\
\hline SIMACOTA & $\begin{array}{c}\text { Estación del } \\
\text { Ferrocarril } \\
\text { Pulpapel }\end{array}$ & $\begin{array}{l}\text { Monumento } \\
\text { Nacional (D) }\end{array}$ & $\begin{array}{c}\text { Resolución } \\
013 \text { I6-VIII- } \\
1994 \text { (Pro- } \\
\text { pone) }\end{array}$ & $\begin{array}{c}\text { Decreto } 746 \\
\text { 24-IV-I996 } \\
\text { (Declara) }\end{array}$ & $\begin{array}{l}\text { Pertenece al Conjunto } \\
\text { Patrimonial de orden } \mathrm{Na} \text { - } \\
\text { cional de las Estaciones de } \\
\text { Pasajeros del Ferrocarril en } \\
\text { Colombia. Siglo XIX - XX }\end{array}$ \\
\hline $\begin{array}{l}\text { SIMACOTA. } \\
\text { VISCAIINA ALTA }\end{array}$ & $\begin{array}{c}\text { Estación del } \\
\text { Ferrocarril } \\
\text { Viscaína }\end{array}$ & $\begin{array}{l}\text { Monumento } \\
\text { Nacional (D) }\end{array}$ & $\begin{array}{c}\text { Resolución } \\
013 \text { I6-VIII- } \\
1994 \text { (Pro- } \\
\text { pone) }\end{array}$ & $\begin{array}{c}\text { Decreto } 746 \\
\text { 24-IV-I996 } \\
\text { (Declara) }\end{array}$ & $\begin{array}{l}\text { Pertenece al Conjunto } \\
\text { Patrimonial de orden } \mathrm{Na} \text { - } \\
\text { cional de las Estaciones de } \\
\text { Pasajeros del Ferrocarril en } \\
\text { Colombia. Siglo XIX - XX }\end{array}$ \\
\hline SOCORRO & $\begin{array}{c}\text { Casa de La } \\
\text { Cultura. Casa } \\
\text { de Berbeo }\end{array}$ & $\begin{array}{l}\text { Monumento } \\
\text { Nacional (D) }\end{array}$ & $\begin{array}{c}\text { Resolución } \\
004 \text { I6-VIII- } \\
\text { I97I (Pro- } \\
\text { pone) }\end{array}$ & $\begin{array}{c}\text { Decreto I77| } \\
\text { 9-IX-197| } \\
\text { (Declara) }\end{array}$ & \\
\hline SOCORRO & $\begin{array}{c}\text { Puente } \\
\text { Comuneros }\end{array}$ & $\begin{array}{l}\text { Bien de Interés } \\
\text { Cultural de Ca- } \\
\text { rácter Nacional }\end{array}$ & & $\begin{array}{c}\text { Resolución } \\
\text { I874 28-XII- } \\
2000 \text { (Declara) }\end{array}$ & \\
\hline SOCORRO & $\begin{array}{c}\text { Sector } \\
\text { Antiguo de } \\
\text { la Ciudad de } \\
\text { Socorro }\end{array}$ & $\begin{array}{l}\text { Monumento } \\
\text { Nacional (D) }\end{array}$ & & $\begin{array}{l}\text { Decreto } 264 \\
\text { I2-II-1963 } \\
\text { (Declara) }\end{array}$ & Sector Urbano Delimitado \\
\hline VÉLEZ & $\begin{array}{l}\text { Colegio Uni- } \\
\text { versitario }\end{array}$ & $\begin{array}{l}\text { Monumento } \\
\text { Nacional (D) }\end{array}$ & & $\begin{array}{c}\text { Decreto } 2333 \\
\text { I5-XI-1973 } \\
\text { (Declara) }\end{array}$ & \\
\hline VÉLEZ & $\begin{array}{l}\text { Estación del } \\
\text { Ferrocarril } \\
\text { Montoyas }\end{array}$ & $\begin{array}{l}\text { Monumento } \\
\text { Nacional (D) }\end{array}$ & $\begin{array}{c}\text { Resolución } \\
013 \text { I6-VIII- } \\
1994 \text { (Pro- } \\
\text { pone) }\end{array}$ & $\begin{array}{c}\text { Decreto } 746 \\
\text { 24-IV-1996 } \\
\text { (Declara) }\end{array}$ & $\begin{array}{l}\text { Pertenece al Conjunto } \\
\text { Patrimonial de orden } \mathrm{Na} \text { - } \\
\text { cional de las Estaciones de } \\
\text { Pasajeros del Ferrocarril en } \\
\text { Colombia. Siglo XIX - XX }\end{array}$ \\
\hline
\end{tabular}

Fuente: Información actualizada a Agosto 15 de 2008, tomada de www.mlncultura.gov.co 

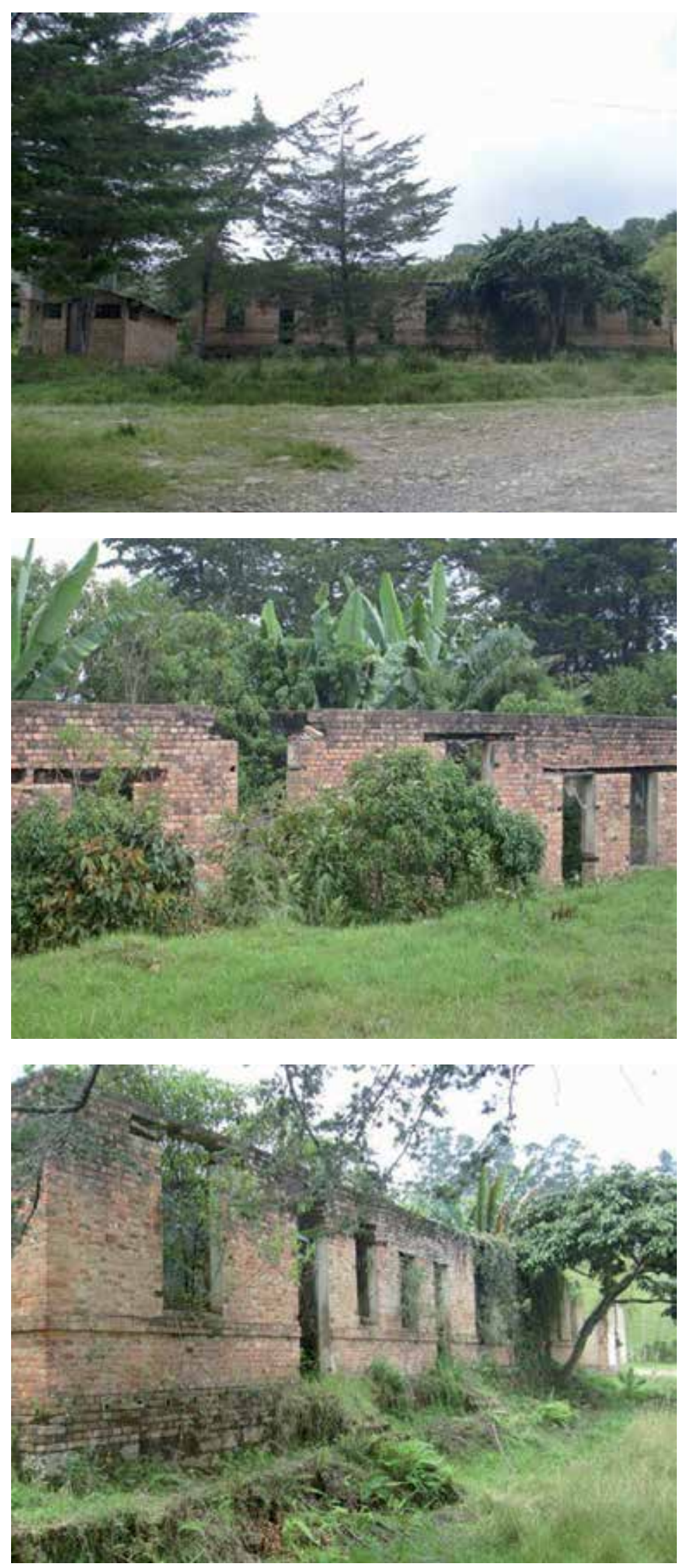

Edificio de la estación de ferrocarril de Los Robles, Puente Nacional - Santander - 2008

Fuente: Archivo del autor 

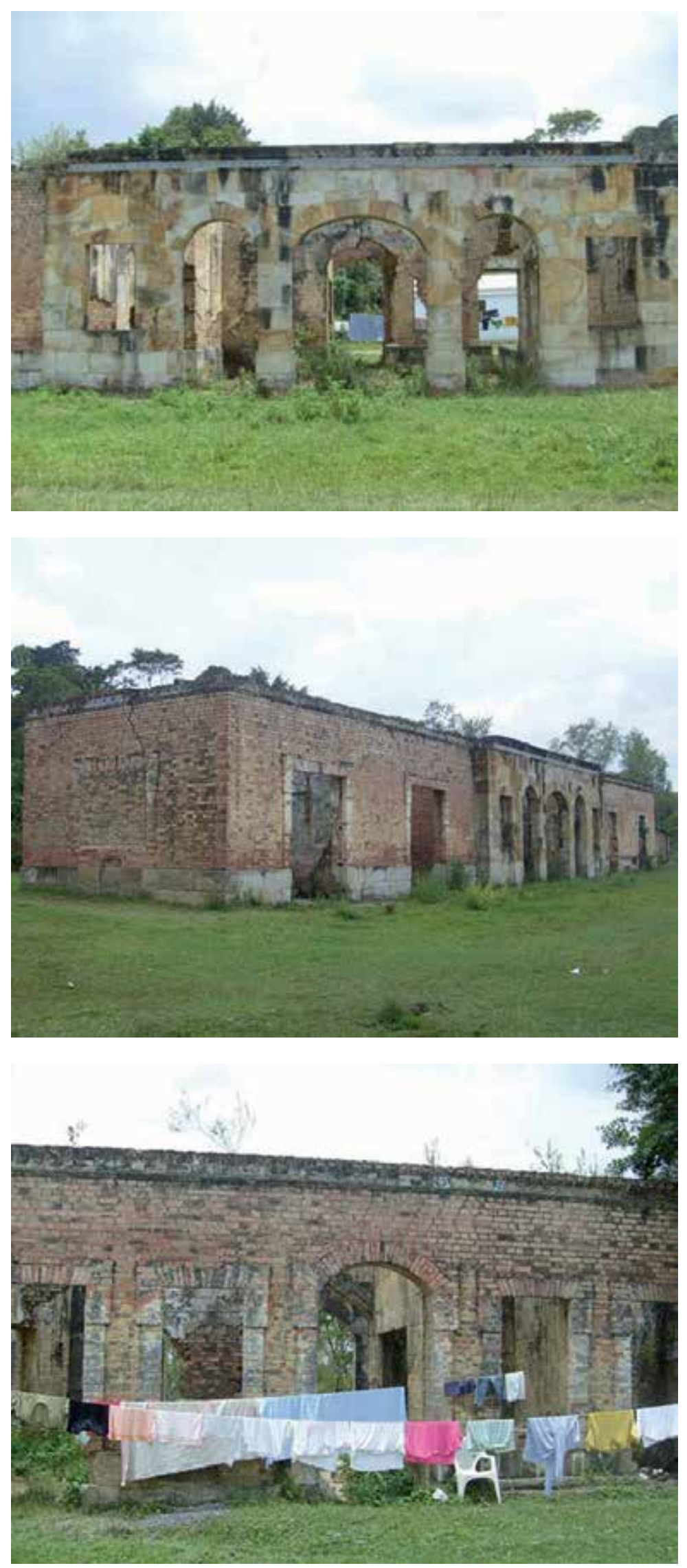

Fuente: Archivo del autor 


\section{LOS ENTES RECTORES DEL PATRIMONIO}

Contrario a lo que de lógica podría esperarse, a la fecha existe en el Departamento un solo ente rector del patrimonio, surgido de la Ley I 185 de 2008 y su Decreto reglamentario 1313 de 2008, que rige todos los aspectos del patrimonio. Con anterioridad funcionó el Centro Filial Santander del Consejo de Monumentos Nacionales, enfocado en el Patrimonio Cultural en general y el Patrimonio arquitectónico y urbanístico en particular.

A nivel municipal, para el año 2009 , sólo dos municipios cuentan con entes encargados del tema: la Junta de Protección del Centro Histórico de Barichara (surgida a partir de la reglamentación del Centro Histórico, el cual se reúne una vez al mes) y la de Bucaramanga, que conformó el Consejo Superior Asesor de Patrimonio ${ }^{4}$, que no presenta actividad constante. Los demás municipios que conforman el departamento, no han informado sobre la existencia de este tipo de organismos y el tema se afronta de acuerdo a cada caso y de forma necesaria, a la conformación de la estructura de las respectivas administraciones municipales, entre los despachos de gobierno, planeación o cultura. A continuación el recuento de funciones $y$ actividades de cada uno de los entes departamentales que intervienen en los procesos relacionados con el patrimonio:

\section{CENTRO FILIAL SANTANDER DEL CONSEJO DE MONUMENTOS NACIONALES}

En 1989 se puso en marcha la subdirección de patrimonio de Colcultura con el propósito de cumplir sus funciones a nivel nacional, para lo cual, decidió crear los centros filiales en las capitales de los departamentos; en Santander se hizo efectivo este hecho en 1991, momento en el cual se crea la junta integrada por el gobernador o su delegado quien la preside, un delegado de monumentos nacionales, el presidente de la Sociedad Colombiana de Arquitectos, un delegado de la Academia de Historia de Santander, encargado de la Secretaría del Consejo, un delegado de los investigadores privados y un delegado de las universidades. De la Secretaría Técnica de la filial se haría cargo el Secretario de Cultura o su delegado (despacho que para el momento existía en Santander).

El Consejo de Monumentos era entonces un ente asesor del gobierno, y para ello el Centro Filial Santander estaba integrado por: el Gobernador del departamento o su representante, un Delegado del Ministro de Cultura, el presidente de la Sociedad Colombiana de Arquitectos o su representante, el Secretario de Planeación Departamental o su delegado, el Secretario de Cultura, Turismo, Recreación y Deporte Departamental (luego reemplazado por el Secretario de Desarrollo Departamental) o su delegado, un representante de la Academia de Historia de Santander, un representante de los investigadores privados y un representante de las Universidades; la Secretaría Técnica estaba a cargo del Director de Patrimonio (reemplazado luego por el Coordinador de Cultura y Turismo).

El Centro Filial de Santander se reunía una vez al mes para estudiar casos y resolver consultas mediante conceptos, los gastos de funcionamiento los debía asumir la Gobernación de Santander, pero debido a lo exiguo del presupuesto, no era posible costear desplazamientos por todo el departamento como sería lo ideal, por lo que se atendían las consultas desde Bucaramanga y en casos muy contados las visitas a los municipios se costearon con recursos personales. A esta paradójica situación se suma otra en la que a los miembros del Centro Filial del Consejo de Monumentos Nacionales les fueron atribuidos factores negativos, acusándolos algunas veces de entorpecer los intentos de preservación, sólo

4 Creado por el Acuerdo 050 del 22 de Noviembre de 2007 
porque se pedía cumplir con la reglamentación y la preservación espacial y urbana en sus proyectos y presentarlos adecuadamente. ${ }^{5}$ Sin embargo esta acusación carecía de fundamento pues la presentación de proyectos estaba reglamentada: los planos, sus contenidos y escalas, estaban debidamente especificados en el documento de la Subdirección de Patrimonio Cultural de Colcultura (hoy Dirección de Patrimonio del Ministerio de Cultura): “Declaratoria y manejo de monumentos nacionales", editado en Julio de 1990, y en el documento "Requisitos y Trámites" del Ministerio de Cultura fechado en 2005; hoy se encuentran reglamentados en el texto del Decreto Nacional 763 de 2009.

Evocar dichos proyectos de importancia regional, sometidos a consideración durante la existencia del Centro Filial Santander del Consejo de Monumentos Nacionales, obliga a hacer mención de los mismos: Reglamentación del Centro Histórico de Barichara (elaborado por el Arquitecto Alberto Saldarriaga Roa para Colcultura), Reglamentación de los marcos de plaza de 12 municipios, Intervención sobre la edificación de la Plaza San Mateo (Bucaramanga), Casa del Libro Total, Declaratoria Como Bien de Interés Cultural Municipal del Edificio del Teatro Santander (con sustento de la historia de la edificación realizado por el Arq. Guillermo Vargas Caballero, representante de la Academia de Historia de Santander ante el Centro Filial), concepto que sustentó la importancia del Festival de Duetos, realizado en Floridablanca y que gracias a la gestión de la filial fue declarado Bien de Interés Cultural avalado por el Ministerio de Cultura.

\section{EL CONSEJO DE PATRIMONIO}

La Ley I 85 de marzo 12 de 2008, crea los consejos departamentales de patrimonio cultural y establece un plazo de 6 meses a partir de su promulgación para dar cumplimiento a estas disposiciones (artículo 4 literal b, parágrafo I y parágrafo transitorio). Es así que mediante Decreto Nacional I313 de abril 23 de 2008, se reglamenta lo anteriormente expuesto, y se les asignan funciones análogas a las del Consejo Nacional de Patrimonio (artículo 10). Sin embargo, a partir de la promulgación de la Ley I I 85 de 2008, surge un inconveniente para la continuidad de funciones del Centro Filial del Consejo de Monumentos, debido a que a nivel departamental el Secretario de Desarrollo Social considera que éste no se encuentra habilitado para funcionar pese a lo estipulado en el parágrafo transitorio, sobre su continuidad hasta la conformación del Consejo Departamental de Patrimonio. La conclusión no es muy alentadora: a la fecha se han redactado 3 Decretos para la conformación del Consejo Departamental de Patrimonio, cada uno de los cuales han presentado errores, debido, aparentemente, al desconocimiento del tema cultural de los encargados de tal tarea y la delgada línea que separa, a nivel conceptual, este Consejo del Consejo Departamental de Cultura.

\section{PROYECTOS DE PATRIMONIO CULTURAL INMUEBLE PARA EL DEPARTAMENTO}

Este diagnóstico pone en evidencia no sólo el estado del patrimonio en el departamento de Santander, sino la necesidad de desarrollar proyectos de preservación de los bienes de interés cultural inmueble. A continuación se menciona un listado de los proyectos pendientes para ejecutar en el departamento:

$5 \quad$ Algunos de los miembros, no funcionarios de la Administración Departamental, de este Consejo han sido: Arq. Inés Villalba de Linares, Dr. Adolfo Harker Peralta, Arq. Alfonso Sanmiguel, Arq. Antonio José Díaz Ardila, Arq. Carlos Cadena Villalobos, Arq. Fabio Agudelo, Arq. Guillermo Vargas Caballero, Arq. Héctor Sarmiento, Arq. Jesús Moreno, Arq. Julián Ignacio Ruiz Orduz, Arq. Luis Ardila Cancino, Arq. Rafael Ernesto Acevedo Serrano, Arq. Samuel Jaimes Botía, Arq. Nahir Pabón Castro. 


\section{PLANES ESPECIALES DE MANEJO Y PROTECCIÓN DE LOS CENTROS HISTÓRICOS DE GIRÓN, SAN GIL, SOCORRO Y BA- RICHARA}

El Departamento cuenta con el dudoso honor de ser el único en el país, en no haber realizado estos proyectos para los cuatro (4) Centros Históricos reconocidos como Bienes de Interés Cultural de Carácter Nacional (Antes Monumentos Nacionales): San Juan Girón, San Gil, Socorro y Barichara. A pesar de ello, existe un convenio con el Ministerio de Cultura desde el año 2005, para la ejecución de estos estudios y a partir de éste, se firmó un convenio entre el Departamento y los Municipios de San Gil, Socorro y Barichara el cual ha contado con reiterados tropiezos surgidos del desconocimiento del tema por parte de los funcionarios asignados al proceso legal, el mayor de los cuales recae en las elevadas exigencias de perfil, experiencia profesional y capacidad de contratación de los equipos de trabajo, lo cual se vio reflejado en las diversas convocatorias para la realización de los estudios de pre diagnóstico realizadas hasta la fecha las cuales debieron ser declaradas desiertas, debido a que este tipo de estudios no es rentable para firmas de fuera del departamento $y$, por lo tanto, no presentaron propuestas, $y$ a que los profesionales del departamento no alcanzaron a cumplir con dichos requerimientos. Recientemente se hizo solicitud de cotizaciones de mercado bajo términos de referencia asesorados por el Ministerio de Cultura y se está en espera de la nueva convocatoria para los estudios de la fase de pre diagnóstico para los tres municipios. Cabe anotar que el Municipio de San Juan Girón que no hizo parte de este convenio, ya realizó el pre diagnóstico pero hace falta la culminación de la formulación y puesta en marcha.

\section{CAMINOS DE SANTANDER}

Algunas vías rurales y urbanas para el uso exclusivo de peatones, ciclistas, semovientes, carretas de tracción animal y similares, así como los caminos indígenas, reales, de herradura, senderos, servidumbres, trochas y similares, fueron protegidos mediante la Ordenanza No. 021 de septiembre 7 del 2006; sin embargo, aún quedan por inventariar y proteger algunos, en otras zonas del departamento.

Sobre este tema se requieren dos acciones puntuales:

- Actualización y terminación del inventario, para incluir otros caminos en la lista de protección.

- Dar cumplimiento a lo estipulado en la Ordenanza No. 02I de septiembre 7 de 2006, sobre aspectos de señalización, resolución y recuperación; restauración, construcción, conservación, uso y permanencia; declaratoria como BIC de ámbito Nacional, inventario y levantamiento cartográfico con base en un Sistema de Posicionamiento Global-GPS, inclusión en los Programas de Turismo y Cultura, adoptar las Estrategias necesarias para la divulgación, Promoción y Concientización de la Importancia de los caminos; actividades que se indican en la citada Ordenanza.

\section{DECLARATORIA DE BIENES DE INTERÉS CULTURAL EN EL DE- PARTAMENTO}

Las conclusiones del Inventario de Bienes Inmuebles de Interés Cultural realizado en el año 2008, recomiendan la declaratoria como Bienes de Interés Cultural de 140 edificaciones de carácter departamental y municipal. Es necesario iniciar por tanto, la realización de los estudios para determinar cuáles de ellas requieren Plan Especial de Manejo y Protección (PEMP), a fin de realizar de inmediato las declaratorias sobre aquellas que no los requieren e 
Fuente: Elaborado por la autora con base en datos cotejados del POT Departamental

Edificio de la estación de ferrocarril de San Benito Nuevo, San Benito - Santander - 2008 Fuente: Archivo del autor iniciar la formulación de los PEMP de aquellas que sí. De igual manera, es necesario iniciar el proceso de sensibilización y asesoría técnica a los municipios para los procesos de este nivel.

\section{REGLAMENTACIONES Y NORMATIZACIONES}

Once municipios y un corregimiento de Santander tienen reglamentado el marco de la plaza principal o "plaza fundacional” (Ver Cuadro 2). Es importante resaltar que la Gobernación de Santander en sus documentos referidos al plan de desarrollo hizo mención de ello para ser tenidos en cuenta al momento de la formulación de los POT respectivos, pero al no haber sido aprobadas estas reglamentaciones por los Concejos Municipales, no fueron tenidas en cuenta por los consultores. En el momento se excluirían del listado los municipios de San Gil y Socorro por estar incluidos estos sectores en las áreas de estudio de los PEMP de esos municipios.

Cuadro 2. Municipios y corregimientos de Santander con reglamentación de su plaza fundacional

\begin{tabular}{|c|c|c|}
\hline \multicolumn{2}{|c|}{ MUNICIPIO } \\
\hline Aratoca & Curití & San Gil \\
\hline Cabrera & Guapotá & Socorro \\
\hline Cepitá & Oiba & Valle de San José \\
\hline Confines & Pinchote & Guane \\
\hline
\end{tabular}

\section{ESTACIONES DE FERROCARRIL}

En el marco del Plan de recuperación de Estaciones Férreas del Ministerio de Cultura, debe hacerse el estudio respectivo para determinar la situación jurídica de los predios y edificaciones, la historia, estado actual de la edificación y propuesta de uso. El Departamento tiene 34 estaciones declaradas Monumento Nacional y I por fuera del listado ya que la vía nunca llegó 6 (Ver cuadro 3.)

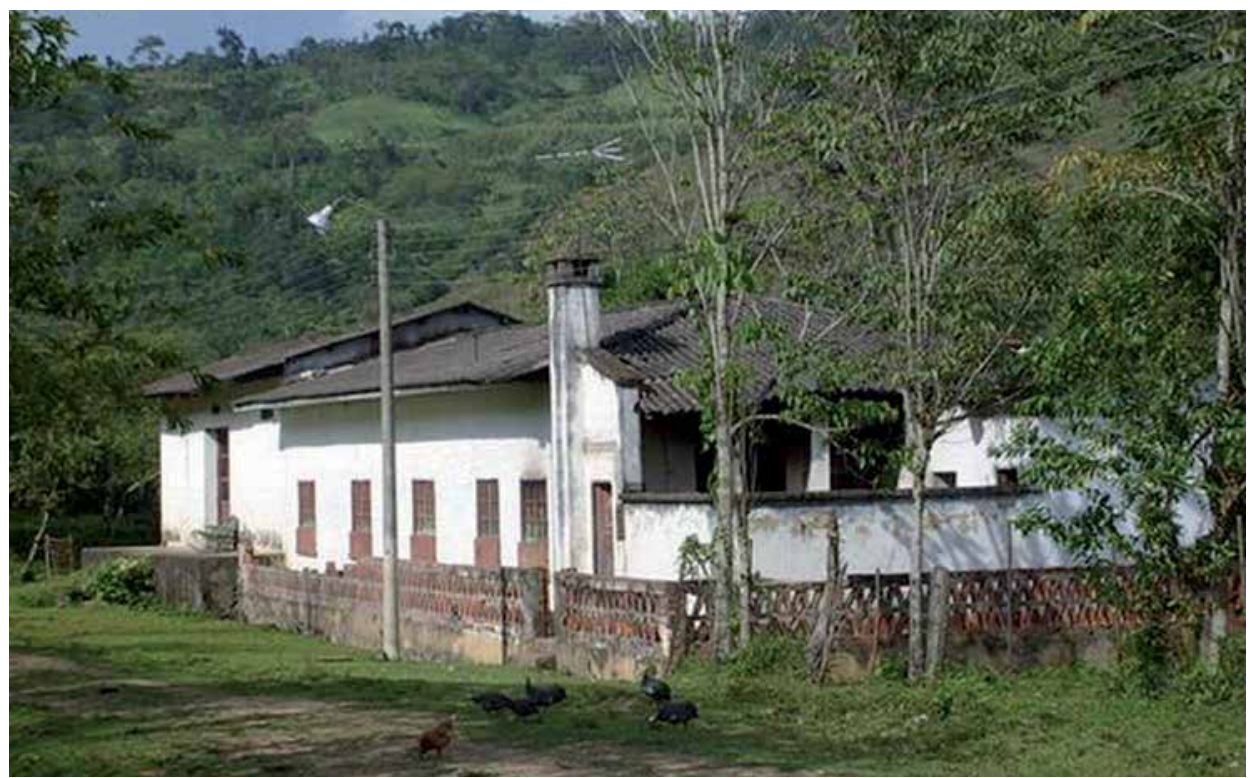

6 A este respecto se puede consultar el Conjunto de las estaciones de pasajeros del ferrocarril en Colombia en la Resolución 013 de 16 de agosto de 1994 
Cuadro 3. Listado de las estaciones de ferrocarril del departamento de Santander

\begin{tabular}{|c|c|c|}
\hline MUNICIPIO & ESTACIÓN DEL FERROCARRIL & OBSERVACIONES \\
\hline Barbosa & Barbosa & $\begin{array}{l}\text { Está siendo intervenida por el Muni- } \\
\text { cipio como base para la Terminal de } \\
\text { Transportes }\end{array}$ \\
\hline \multirow{3}{*}{ Barrancabermeja } & Barrancabermeja & \\
\hline & Cuatrobocas & \\
\hline & Pénjamo & \\
\hline Bucaramanga & Café Madrid & $\begin{array}{l}\text { Invadida por desplazados, proble- } \\
\text { mas de orden público. El Municipio } \\
\text { no dejó espacio de aislamiento con } \\
\text { el proyecto de vivienda de interés } \\
\text { social. Amenazada por el proyecto } \\
\text { vial de Autopistas de Santander. }\end{array}$ \\
\hline \multirow{3}{*}{ Cimitarra } & Carare & $\begin{array}{l}\text { En jurisdicción del Municipio de } \\
\text { Puerto Parra. En funcionamiento } \\
\text { INCO }\end{array}$ \\
\hline & Puerto Olaya & $\begin{array}{l}\text { Se entregó a INVÍAS en el 2000, hay } \\
\text { una familia viviendo. }\end{array}$ \\
\hline & San Juan & En funcionamiento INCO \\
\hline Girón & Palmas & \\
\hline \multirow{4}{*}{ Lebrija } & Chuspas & \\
\hline & Conchal & \\
\hline & Puerto Santos & \\
\hline & Vanegas & \\
\hline \multirow{5}{*}{ Puente Nacional } & Límites & En Ruinas \\
\hline & Guayabo & En Ruinas \\
\hline & Los Robles & $\begin{array}{l}\text { En Ruinas. Hay problemas por apro- } \\
\text { piación privada del terreno. }\end{array}$ \\
\hline & Providencia & En Ruinas \\
\hline & Puente Nacional & En Ruinas \\
\hline \multirow{5}{*}{ Puerto Wilches } & El Cruce & \\
\hline & García Cadena & \\
\hline & González - Vásquez & \\
\hline & Puerto Wilches & \\
\hline & Sogamoso & \\
\hline Rionegro & Lebrija & \\
\hline \multirow{6}{*}{ Sabana de Torres } & Celestino Mutis & \\
\hline & Comuneros & \\
\hline & Eloy Valenzuela & \\
\hline & Provincia & \\
\hline & Sabana de Torres & \\
\hline & Sabaneta & \\
\hline \multirow{3}{*}{ Simacota } & Opón & \\
\hline & Pulpapel & \\
\hline & Viscaína & \\
\hline Vélez & Montoyas & $\begin{array}{l}\text { En jurisdicción del Municipio de } \\
\text { Puerto Parra. En Ruinas, casi no es } \\
\text { identificable el sitio }\end{array}$ \\
\hline
\end{tabular}

Fuente: Creación propia con base en el listado del Ministerio de Cultura y las visitas realizadas durante la realización del inventario de Bienes de Interés Cultural Inmueble de Carácter Patrimonial del Departamento de Santander 


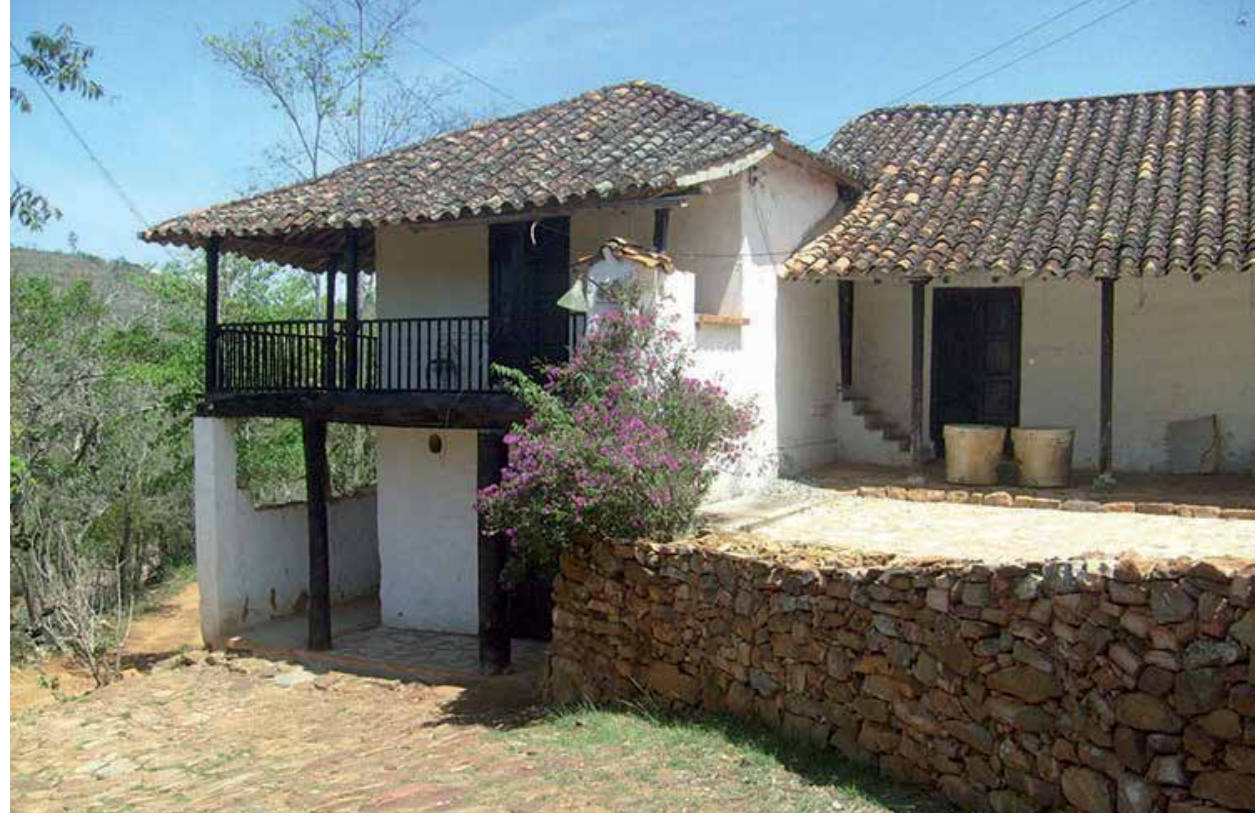

Es preciso añadir a este listado la estación de San Benito Nuevo, ubicada en el municipio de San Benito en la Provincia de Vélez, última estación construida en el Departamento y a la cual la vía férrea nunca llegó.

\section{PROPUESTA DE PROYECTOS SOBRE PATRIMONIO CULTURAL INMUEBLE}

Acorde a la magnitud del tema, y según lo expresado en líneas anteriores, se propuso una lista de proyectos sobre patrimonio cultural inmueble que pueden ser ejecutados por la presente administración y que encajan en lo estipulado en el Plan de Desarrollo Departamental Santander Incluyente.

\section{FORMULACIÓN DE LOS PEMP DE LOS BIC DEPARTAMENTALES}

A partir del Inventario de Bienes Inmuebles de Interés Cultural del departamento realizado en el 2008, surge el listado de 140 edificaciones para ser declaradas BIC de carácter municipal y/o departamental, algunas de las cuales requieren la formulación del Plan Especial de Manejo y Protección (PEMP). Para ello se precisan las siguientes acciones:

- Formular los PEMP de los BIC departamentales

- Asesorar a los municipios en la formulación de los PEMP para soportar la declaratoria según lo estipulado en la Ley I I 85 de 2008 y su Decreto reglamentario 763 de 2009

\section{PROYECTO PLANES DE MANEJO DE EDIFICACIONES DECLA- RADAS BIC QUE NO REQUIEREN PEMP}

Si bien, la normatización que promulga la ley, está orientada a que los PEMP se realicen en las edificaciones o sectores de ciudades declarados BIC que tengan ciertas características de riesgo o afectación, los otros $\mathrm{BIC}$ requieren que se planifique toda la actuación para su preservación y sostenibilidad en el futuro, como estudios e intervenciones. Se proponen como acciones para tener en cuenta: 
Establecer un Plan de Manejo para las edificaciones declaradas Bien de Interés Cultural, que no requieran PEMP, con la elaboración de un diagnóstico técnico que permita identificar los actuales deterioros, darle una solución adecuada y prevenir aquellos que puedan presentarse en el futuro y que puedan afectar la estabilidad y la calidad del inmueble, que cumpla con los lineamientos de la Intervención ante el Consejo Nacional de Patrimonio, en consideración a ser estos inmuebles un Bienes de Interés Cultural Patrimonial de carácter Departamental y/o Municipal y permitir el seguimiento de su óptimo mantenimiento.

\section{NORMATIZACIÓN DE LA REGLAMENTACIÓN DE MARCOS DE PLAZA}

Once municipios y un corregimiento de Santander tienen reglamentado el marco de la plaza principal o "plaza fundacional". Es importante resaltar que la Gobernación de Santander en sus documentos referidos al plan de desarrollo hace mención de ello para ser tenidos en cuenta al momento de la formulación de los POT respectivos. Estos estudios no fueron adoptados por los municipios. En el siguiente cuadro se consigna la información pertinente a este tópico:

Cuadro 4. Reglamentación de marco de plaza

\begin{tabular}{|l|l|}
\hline PROVINCIA & \multicolumn{1}{|c|}{ MUNICIPIO } \\
\hline \multirow{4}{*}{ Guanentá } & Aratoca \\
\cline { 2 - 2 } & Cabrera \\
\cline { 2 - 2 } & Cepitá \\
\cline { 2 - 2 } & Confines \\
\cline { 2 - 2 } & Curití \\
\cline { 2 - 2 } & Guapotá \\
\cline { 2 - 2 } & Pinchote \\
\cline { 2 - 2 } & Valle de San José \\
\cline { 2 - 2 } & Guane \\
\hline Comunera & Oiba \\
\hline
\end{tabular}

Reglamentar los marcos de plaza amerita revisar y actualizar la normativa existente, así como diseñar y establecer la normatividad urbana en el área reglamentada para cada uno de los municipios.

\section{PROYECTO DE RECUPERACIÓN DE LAS ESTACIONES DE FE- RROCARRIL}

Inscrito en el programa de recuperación de las estaciones de ferrocarril del Ministerio de Cultura, este proceso se convierte en la necesidad de preservar la memoria de una época del desarrollo de la nación (Ver cuadro 5.) Para ello se requieren las siguientes acciones:

- Determinar la propiedad de la estación y del terreno donde se encuentra ubicada, el tamaño del predio correspondiente a la estación y sus dependencias.

- Aclarar los aspectos jurídicos del terreno y las edificaciones

- Realizar el estudio histórico de cada edificación

- Formular el anteproyecto arquitectónico de la propuesta de uso para la recuperación de cada edificación. 
Cuadro 5. Estaciones incluidas en el Proyecto

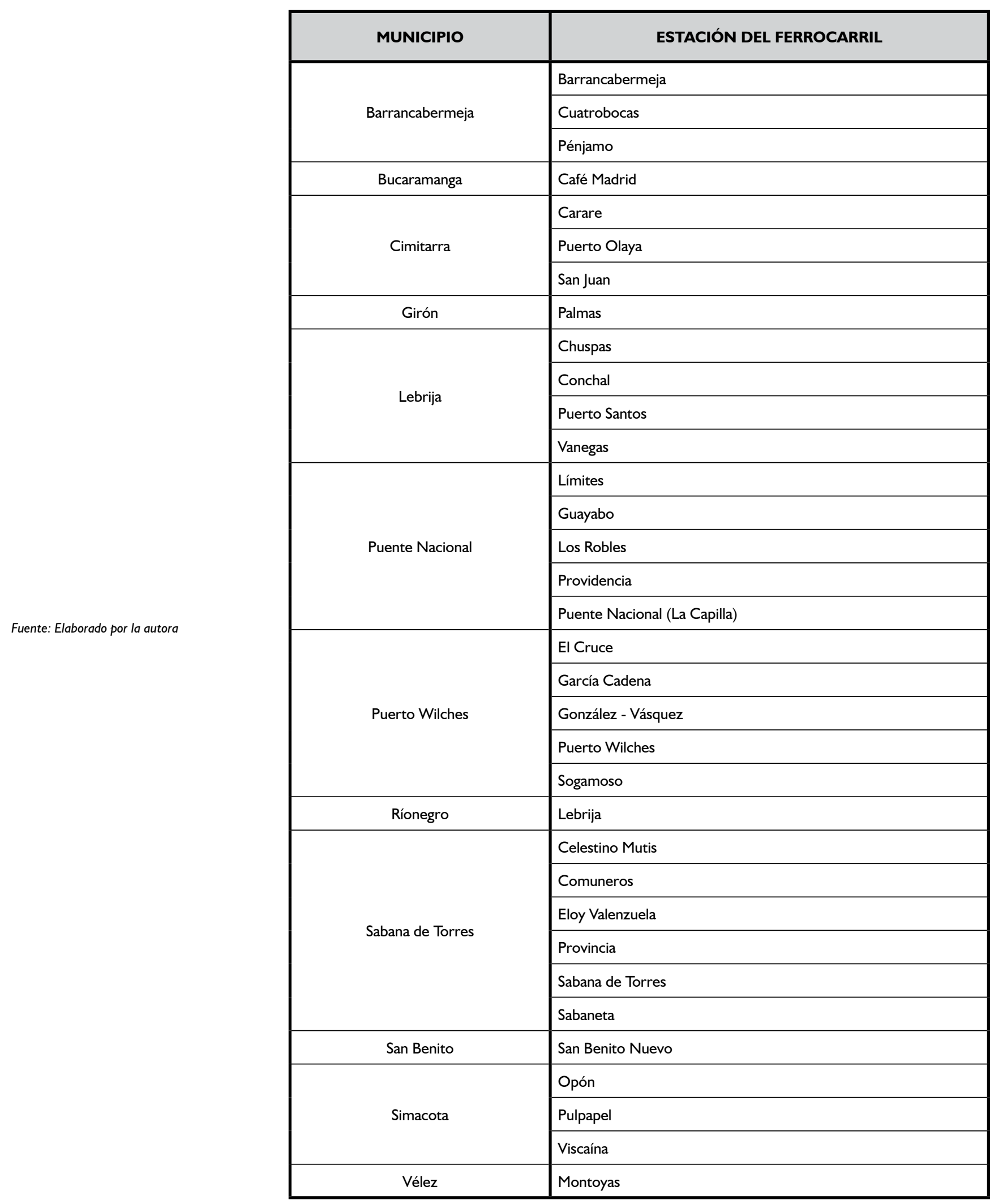




\section{PROYECTOS CONVENIO ESTADO - IGLESIA}

A partir del convenio entre el Estado colombiano y la Iglesia católica para la protección del patrimonio cultural de carácter religioso, surge la necesidad de identificar, inventariar y reglamentar este patrimonio para su protección, de allí la idea de dar inicio al proyecto de inventario de las edificaciones religiosas erigidas en territorio colombiano. Se precisan en torno a este propósito el desarrollo de la valoración inventario de las edificaciones religiosas del departamento de Santander. Se incluye en este ítem el proyecto Monografía de las edificaciones religiosas de Santander, el cual amerita el desarrollo de una investigación histórica que lo soporte y la realización de visitas de campo a las edificaciones religiosas del departamento con el fin de publicar una monografía sobre nuestra arquitectura religiosa.
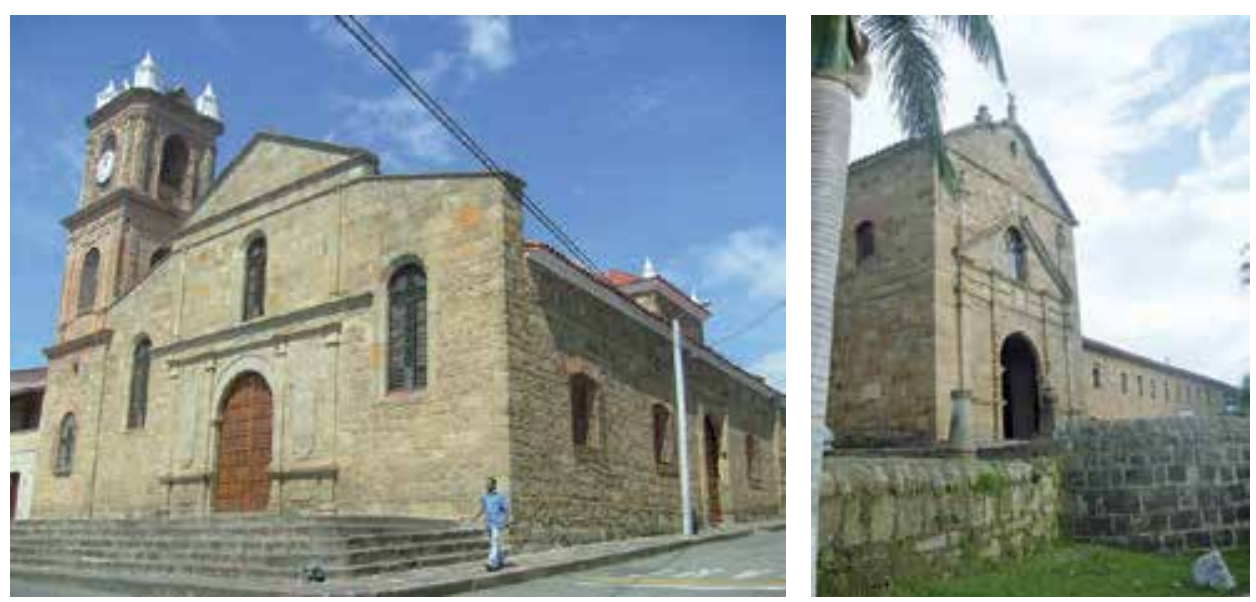

Iglesia de Nuestra Señora de Chiquinquirá, Socorro-Santander - 2009

Fuente: Archivo del autor

Iglesia de Santa Bárbara, Socorro-Santander - 2009

Fuente: Archivo del autor

\section{PROYECTO DE SENSIBILIZACIÓN SOBRE PATRIMONIO CUL- TURAL INMUEBLE}

Se propone realizar un taller de sensibilización y capacitación en las cabeceras de provincia, para el caso de la provincia de Soto, se determinará un municipio diferente a la capital de la provincia y los integrantes del Área Metropolitana de Bucaramanga. Cada evento está diseñado como un Seminario - Taller de dos días de duración, para ser realizado entre sábado y domingo en sesiones de 8 horas diarias. Por lo tanto, la comunidad del municipio encuentra su campo de participación con la asistencia a los eventos, la identificación de situaciones locales, la conformación de grupos para la divulgación y las veedurías ciudadanas que se establezcan a partir de la realización del evento.

\section{CONCLUSIONES}

Si bien el departamento de Santander ha iniciado un proceso que reconoce la existencia del patrimonio cultural inmueble, la consolidación de éste aún requiere recorrer un camino liderado por sus gobernantes en su manifiesta voluntad política marcada por el Plan Departamental de Cultura que debe encontrar eco en los niveles municipales, orientado en un principio al reconocimiento y apropiación social por parte de la comunidad y a la inversión de los recursos de cultura en proyectos que apoyen las intervenciones para su recuperación y sostenibilidad en el tiempo. Por otra parte, la existencia de entidades de orden legal que regulan el patrimonio cultural en el departamento, está condicionada a la "voluntad real" de las administraciones de las que dependen para poder ejercer las funciones asignadas por la ley y para que así sus determinaciones sean acatadas y respetadas como corresponde a su potestad. 
A esto se añade una situación paradójica ya que a pesar de que el Plan Departamental de Cultura "Santander CREA" 2009 - 2019 y el Plan Departamental de Desarrollo 2008 - 20II "Santander Incluyente", sitúen al patrimonio cultural en un lugar preponderante para los procesos de identidad cultural, el tema del patrimonio cultural inmueble no tiene la suficiente relevancia en el ámbito de la programación de inversión tanto en estudios como en ejecuciones, ya que su enfoque está limitado por la visión del bicentenario de la independencia. De igual modo, los listados, a veces interminables, de bienes que poseen valores de tipo histórico, cultural, social, artístico, arquitectónico o urbano se contraponen a la focalización de la inversión de los recursos de dinero en dos o a lo sumo tres proyectos en el territorio del departamento, dejando de lado los demás BIC inmuebles, que en algunos casos requieren de inversiones menores en reparación y mantenimiento de plantas físicas y que en la mayoría de los casos, lo que se requiere es normatización y control sobre las intervenciones en los mismos a partir de estudios técnicos y de documentación que los pongan en relevancia para su apropiación social, e igualmente su inclusión y normatización en los planes de ordenamiento territorial, como el elemento estructurante que es del ordenamiento territorial.

En consecuencia, la visión del aprovechamiento del patrimonio cultural inmueble, como un componente estratégico para el desarrollo de la actividad turística en el departamento, requiere que, adicional a las políticas de Estado, la academia se incorpore con el manejo trans-disciplinar que puede proveer la interinstitucionalidad de los programas de arquitectura, historia y turismo que se ofrecen en universidades locales como la Universidad Santo Tomás Bucaramanga, la Universidad Industrial de Santander, Universidad Autónoma de Bucaramanga, así como el Servicio Nacional de Aprendizaje.

De cualquier modo, la propuesta de proyectos sobre patrimonio cultural inmueble que aquí se presenta en consideración, es tan sólo una pequeña muestra de lo que se puede realizar en esta materia, pero no lo es todo, pues con respecto al patrimonio cultural inmueble del Departamento de Santander casi todo está por hacer.

\section{BIBLIOGRAFÍA}

República de Colombia. Constitución Política de Colombia. 1991

República de Colombia. Ley 397 de 1997 “Ley General de Cultura”

República de Colombia. Ley 388 de 1987 "Ley de Ordenamiento Territorial”

República de Colombia. Ley 1 I 85 de 2008 "Por la cual se modifica y adiciona la Ley 397 de 1997 - Ley General de Cultura - y se dictan otras disposiciones"

República de Colombia. Decreto 763 del 2009 "Por el cual se reglamentan parcialmente las leyes 814 de 2003 y 397 de 1997 modificada por medio de la Ley I I 85 de 2008, en lo correspondiente al Patrimonio Cultural de la Nación de naturaleza material"

República de Colombia. Decreto 1313 de 2008 "por el cual se reglamenta el artículo $7^{\circ}$ de la Ley 397 de 1997, modificado por el artículo $4^{\circ}$ de la Ley 1 I 85 de 2008, relativo al Consejo Nacional de Patrimonio Cultural" 
República de Colombia. Decreto 1747 de 2003, Por el cual se modifica la planta de personal del Ministerio de Cultura.

República de Colombia. Decreto 1746 de 2003, Por el cual se determinan los objetivos y estructura orgánica del Ministerio de Cultura y se dictan otras disposiciones.

República de Colombia. Decreto 1479 de 1999, Por el cual se modifica el Decreto 3048 de 1997. Integración del Consejo de Monumentos Nacionales.

República de Colombia. Decreto I I 26 de 1999, Por el cual se reestructura el Ministerio de Cultura.

República de Colombia. Decreto 853 de 1998, Por el cual se declara la celebración del Día Nacional del Patrimonio Cultural, en todo el territorio colombiano y se dictan otras disposiciones.

República de Colombia. Decreto 3048 de 1997, Por el cual se reglamenta la composición, funciones y régimen de sesiones del Consejo de Monumentos Nacionales y se dictan otras disposiciones.

República de Colombia. Decreto 1974 de 1997, Por el cual se fusiona la Subdirección de Monumentos Nacionales del Instituto Nacional de Vías al Ministerio de la Cultura.

Departamento de Santander. Plan de Ordenamiento Territorial.

Departamento de Santander. Plan de Desarrollo Departamental 2008 - 201 I "Santander Incluyente"

Departamento de Santander. Plan estratégico de Cultura 2009 - 2019 "Santander CREA"

Asamblea Departamental de Santander. Ordenanza N 02I de septiembre 7 del 2006.

CONSEJO DE MONUMENTOS NACIONALES - Centro Filial Santander. Informe arquitecta Inés Villalba. S.F.

Concejo municipal de Bucaramanga. Acuerdo 050 de Noviembre 22 de 2007. Por el cual se crea el Consejo superior asesor de patrimonio cultural y se dictan otras disposiciones.

República de Colombia. Ministerio de Cultura, Dirección de Patrimonio. Manual para Inventario de Bienes Culturales Inmuebles. Bogotá, Imprenta Nacional, 2005. 